Supplementary Figures 

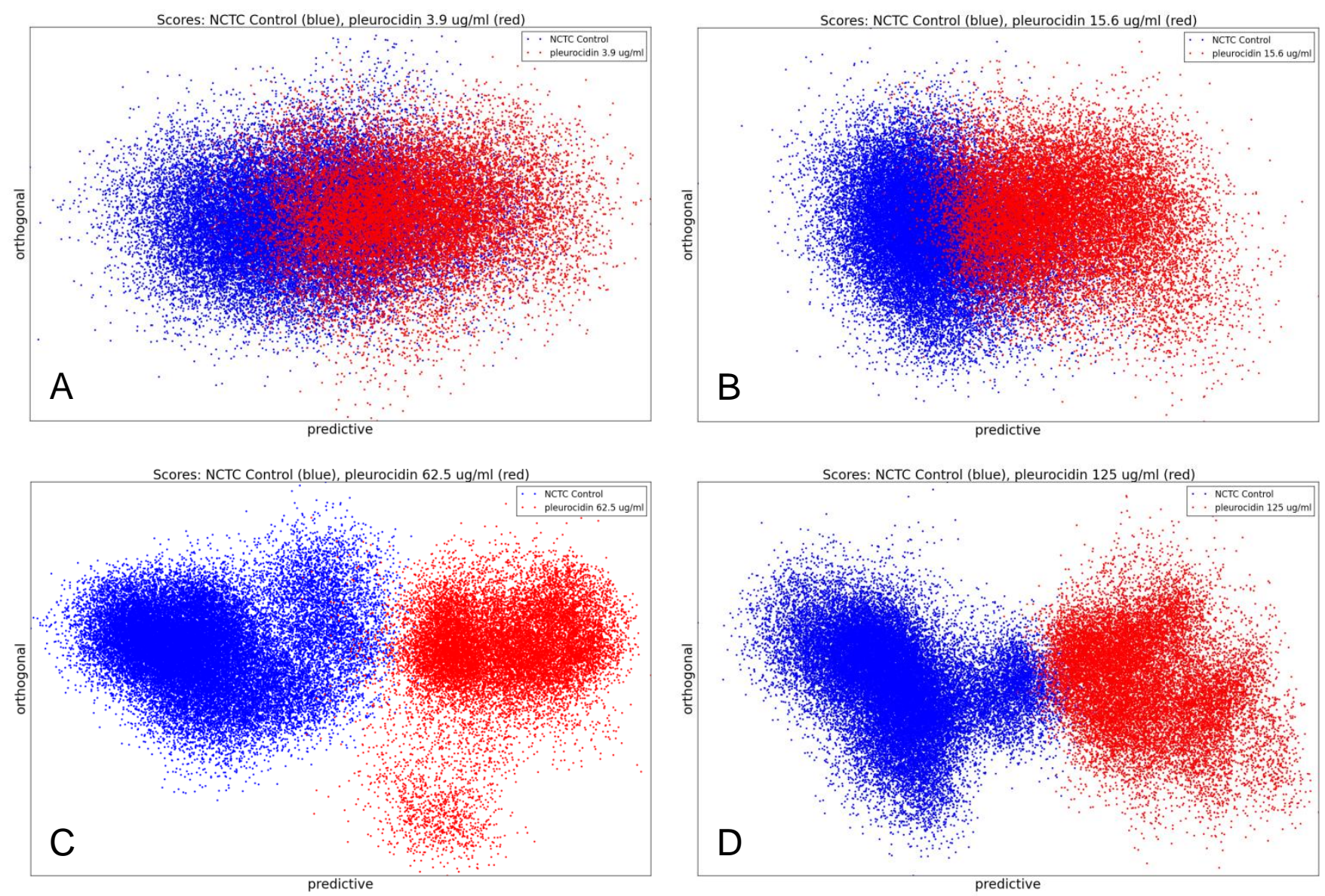

Supplementary Figure 1.1. OPLS-DA scores for comparisons of ${ }^{1} \mathrm{H}$ HR-MAS NMR spectra of control $E$. coli NCTC 9001 and those challenged with pleurocidin at $3.9 \mu \mathrm{g} / \mathrm{ml}(\mathbf{A}), 15.6 \mu \mathrm{g} / \mathrm{ml}$ (B), $62.5 \mu \mathrm{g} / \mathrm{ml}$ (C) and $125 \mathrm{\mu g} / \mathrm{ml}$ (D). In all panels blue dots represent scores from unchallenged bacteria while red dots represent scores from the respective treatments. 

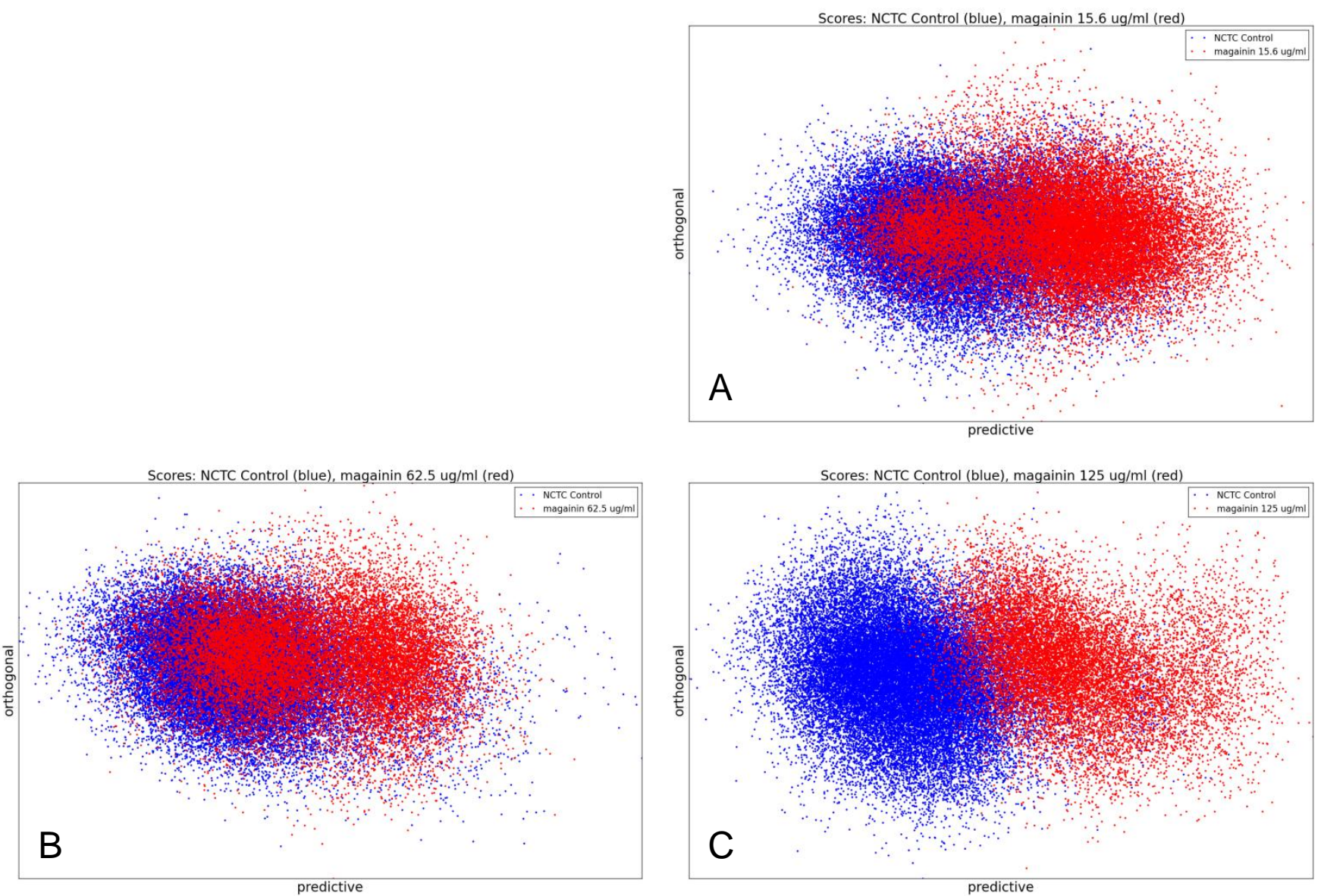

Supplementary Figure 1.2. OPLS-DA scores for comparisons of ${ }^{1} \mathrm{H}$ HR-MAS NMR spectra of control E. coli NCTC 9001 and those challenged with magainin 2 at $15.6 \mu \mathrm{g} / \mathrm{ml}$ (A), $62.5 \mu \mathrm{g} / \mathrm{ml}$ (B) and $125 \mu \mathrm{g} / \mathrm{ml}$ (C). In all panels blue dots represent scores from unchallenged bacteria while red dots represent scores from the respective treatments. 

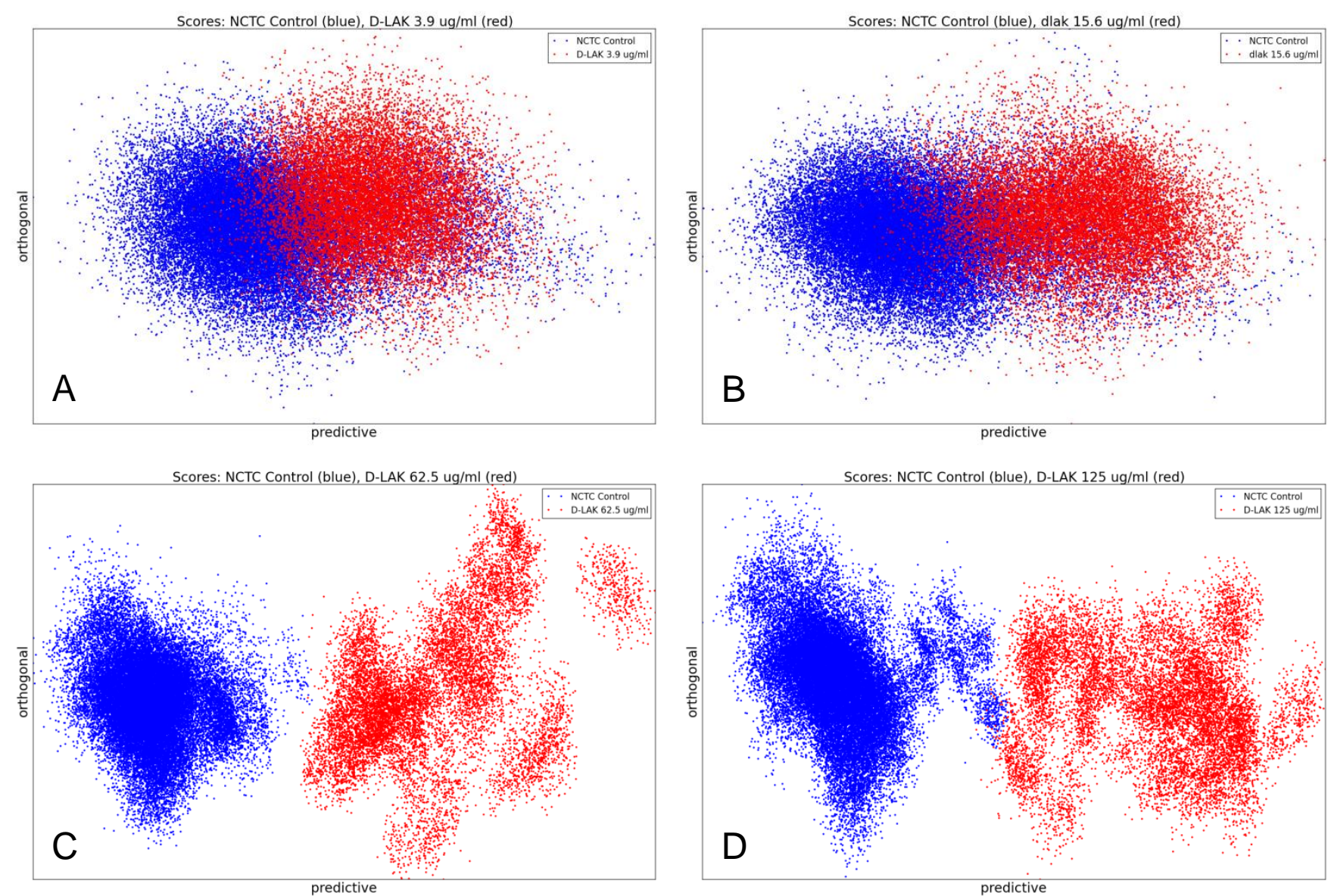

Supplementary Figure 1.3. OPLS-DA scores for comparisons of ${ }^{1} \mathrm{H}$ HR-MAS NMR spectra of control E. coli NCTC 9001 and those challenged with D-LAK120-AP13 at $3.9 \mu \mathrm{g} / \mathrm{ml}$ (A), $15.6 \mu \mathrm{g} / \mathrm{ml}$ (B), $62.5 \mu \mathrm{g} / \mathrm{ml}$ (C) and $125 \mu \mathrm{g} / \mathrm{ml}$ (D). In all panels blue dots represent scores from unchallenged bacteria while red dots represent scores from the respective treatments. 


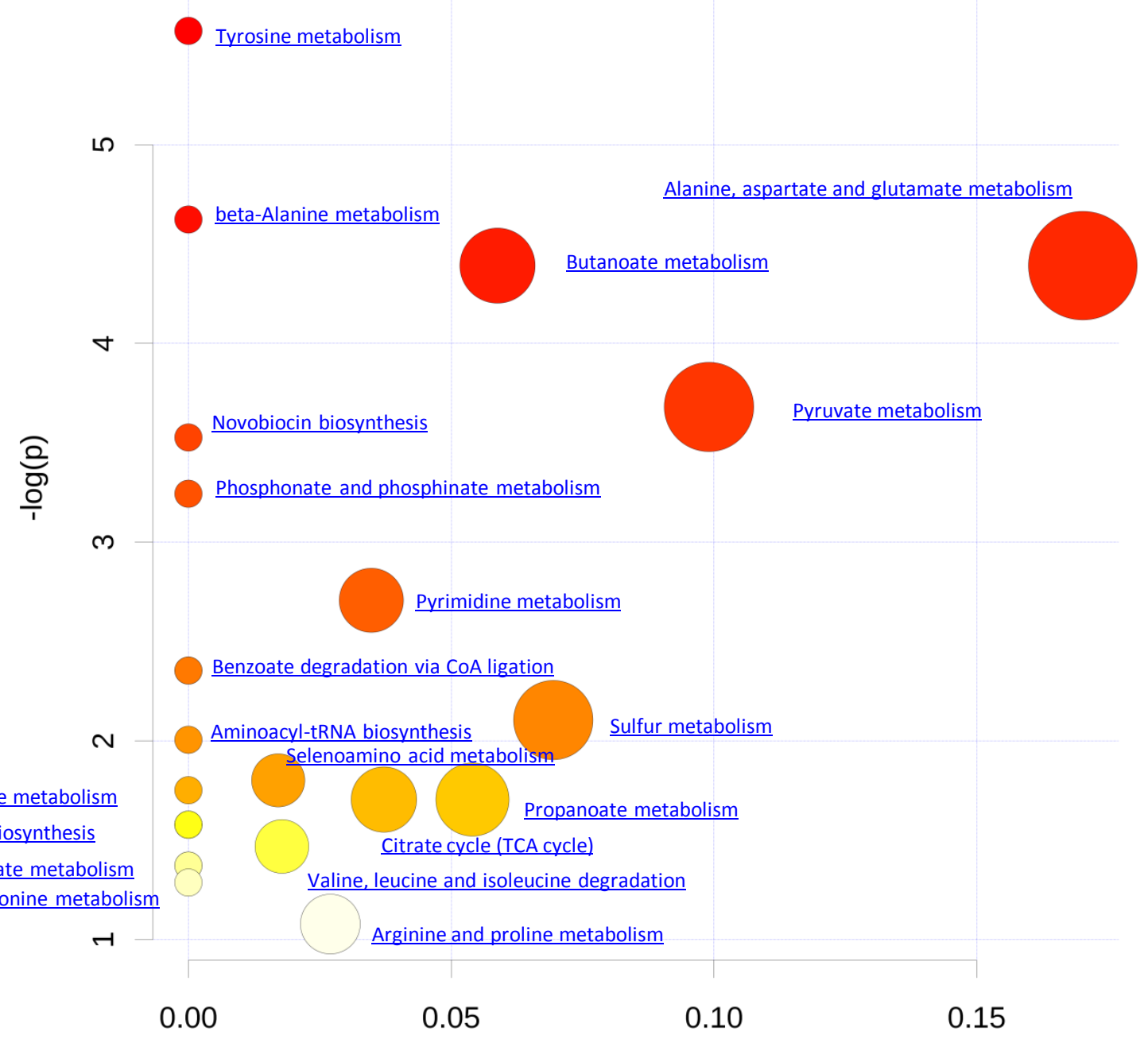

\section{Pathway Impact}

Supplementary Figure 2.1. Network pathway analysis by MetaboAnalyst software showing matched pathways according to $p$-values from pathway enrichment analysis and pathway impact values from pathway topology analysis based on the identified NMR resonances distinguishing control from the treatment with pleurocidin $(62.5 \mu \mathrm{g} / \mathrm{ml})$. 


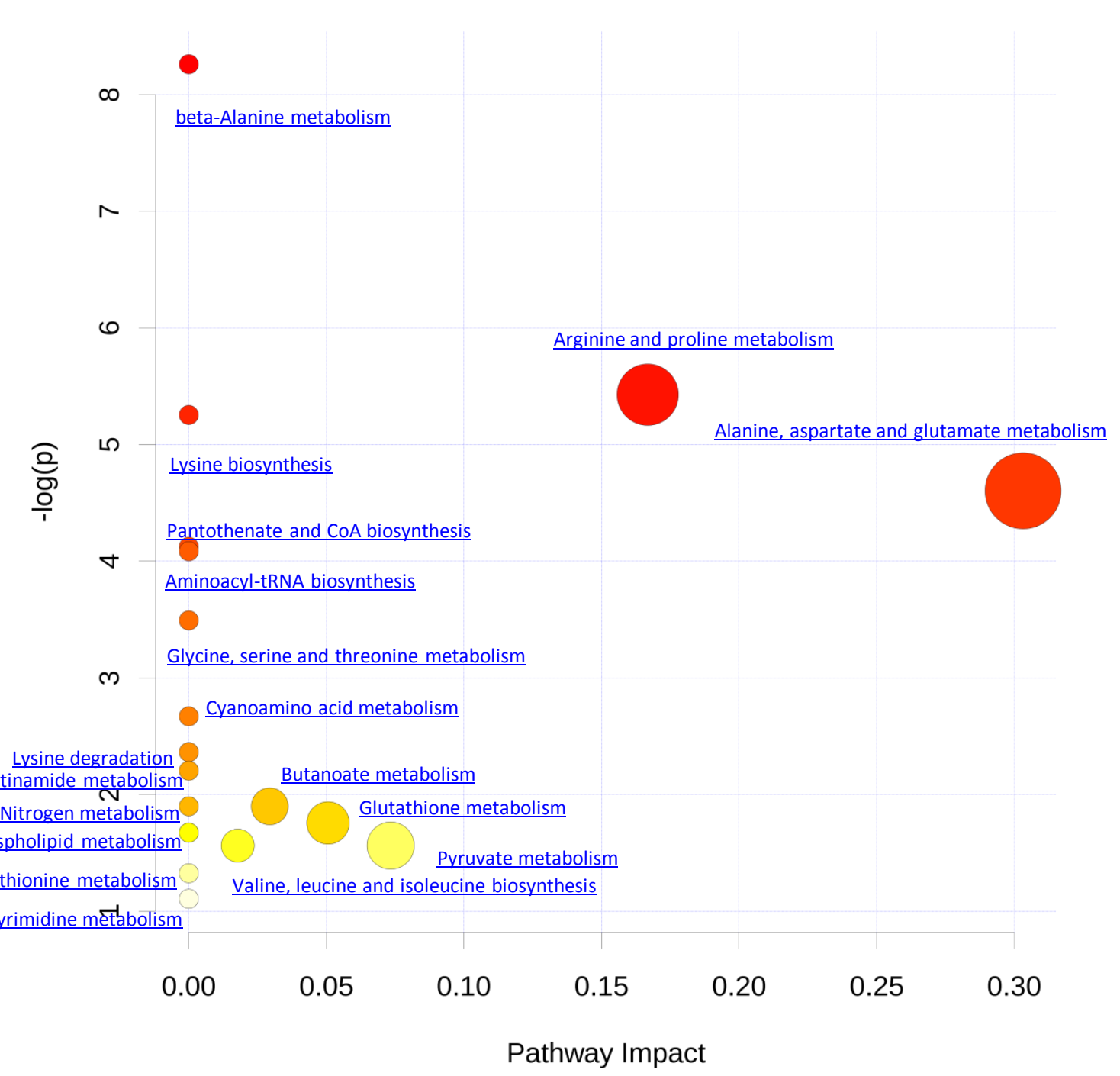

Supplementary Figure 2.2. Network pathway analysis by MetaboAnalyst software showing matched pathways according to $p$-values from pathway enrichment analysis and pathway impact values from pathway topology analysis based on the identified NMR resonances distinguishing control from the treatment with magainin $2(125 \mu \mathrm{g} / \mathrm{ml})$. 
- beta-Alanine metabolism

$\infty$

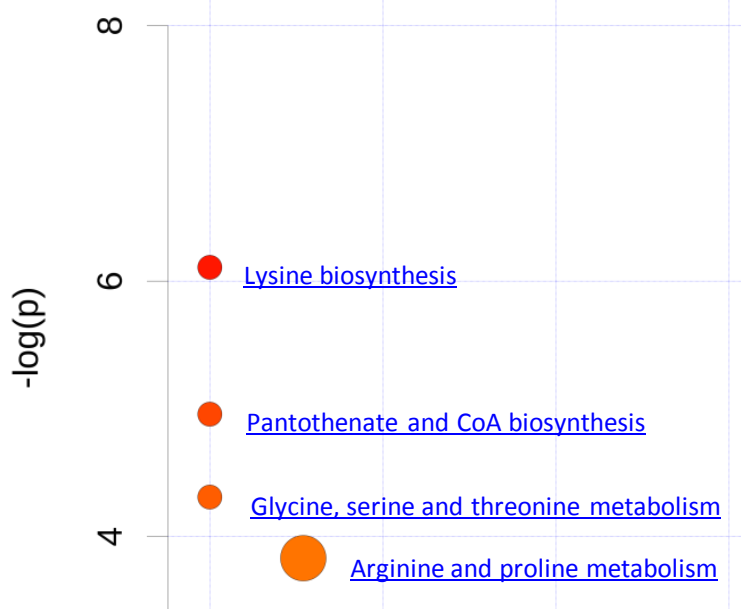

Alanine, aspartate and glutamate metabolism

Cyanoamino acid metabolism Aminoacyl-tRNA biosynthesis

Nicotinate and nicotinamide metabolism

Nitrogen metabolism

Glycerophospholipid metabolis

Cysteine and methionine metabolism

Pyrimidine metabolism

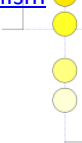

Butanoate metabolism

$\begin{array}{lll}0.00 & 0.05 \quad 0.10\end{array}$

Pathway Impact

Supplementary Figure 2.3. Network pathway analysis by MetaboAnalyst software showing matched pathways according to $p$-values from pathway enrichment analysis and pathway impact values from pathway topology analysis based on the identified NMR resonances distinguishing control from the treatment with D-LAK120-AP13 $(15.6 \mu \mathrm{g} / \mathrm{ml})$. 
Aminoacyl-tRNA biosynthesis

Benzoate degradation via CoA ligation

Lysine degradation

Lysine biosynthesis

beta-Alanine metabolism

Phenylalanine metabolism

\section{tatabolism}

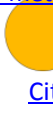

Propanoate metabolism

Citrate cycle (TCA cycle)

Valine, leucine and isoleucine biosynthesis

Arginine and proline metabolism
0.00
0.05
0.10
0.15

Pathway Impact

Supplementary Figure 2.4. Network pathway analysis by MetaboAnalyst software showing matched pathways according to $p$-values from pathway enrichment analysis and pathway impact values from pathway topology analysis based on the identified NMR resonances distinguishing control from the treatment with Buforin II $(250 \mu \mathrm{g} / \mathrm{ml})$. 
A

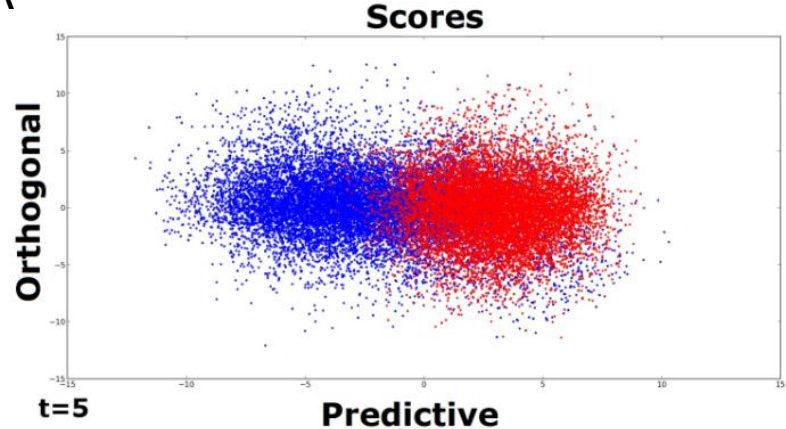

Scores

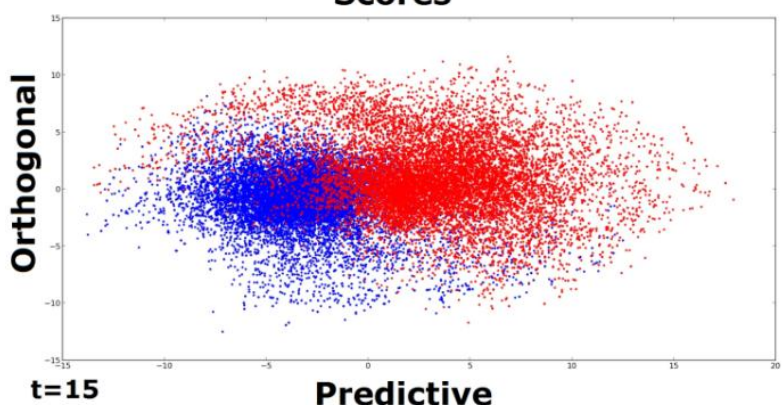

B

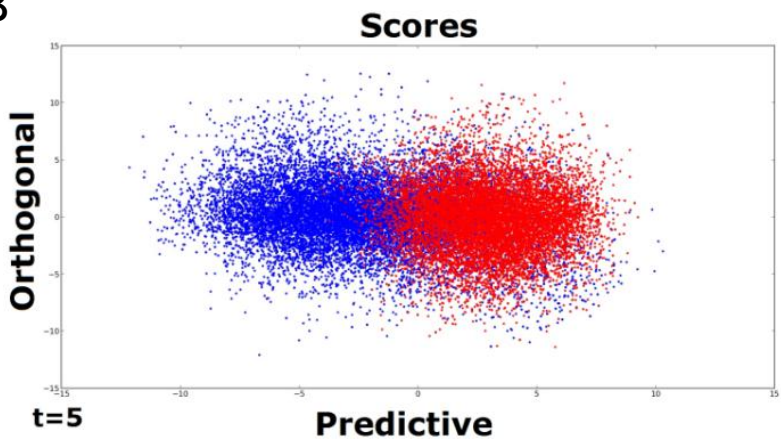

Scores

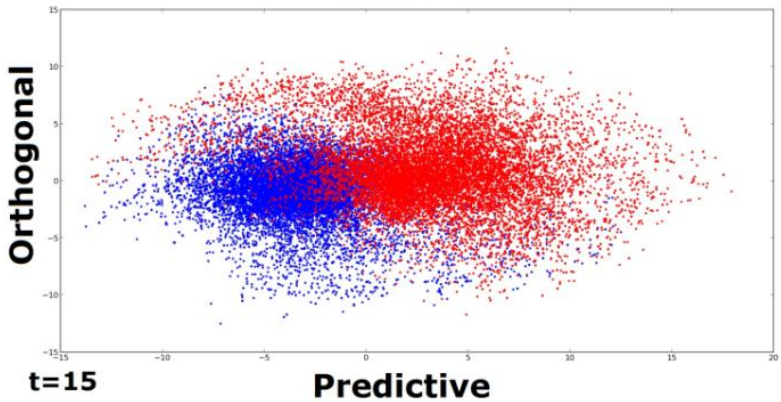

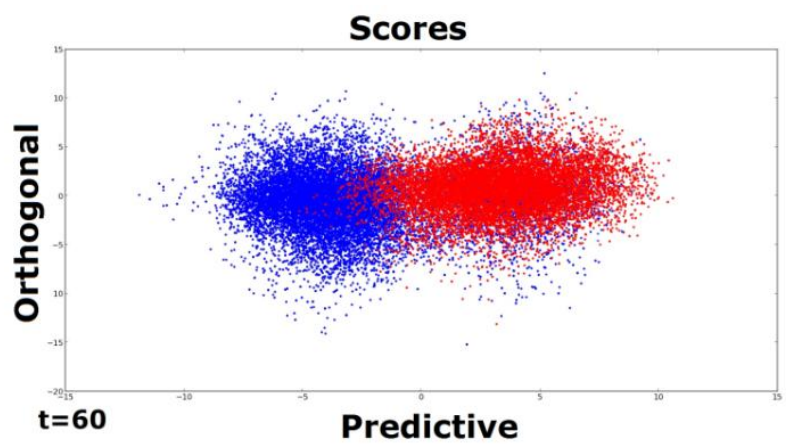

Scores

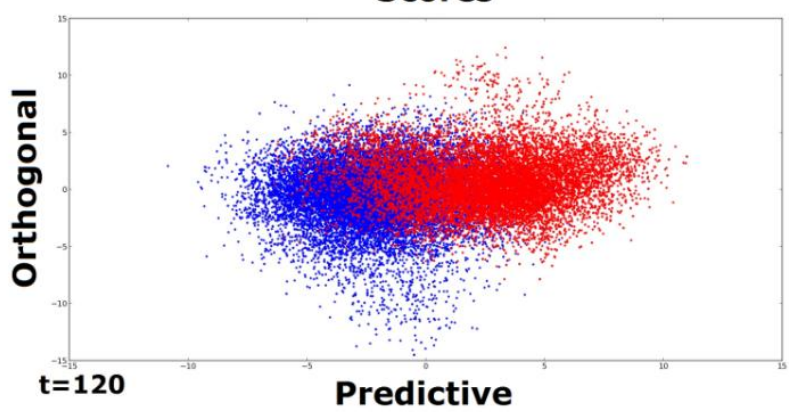

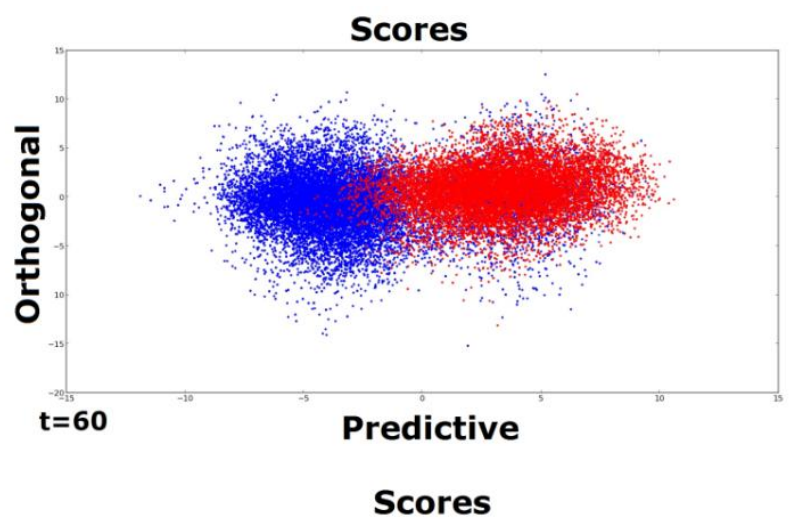

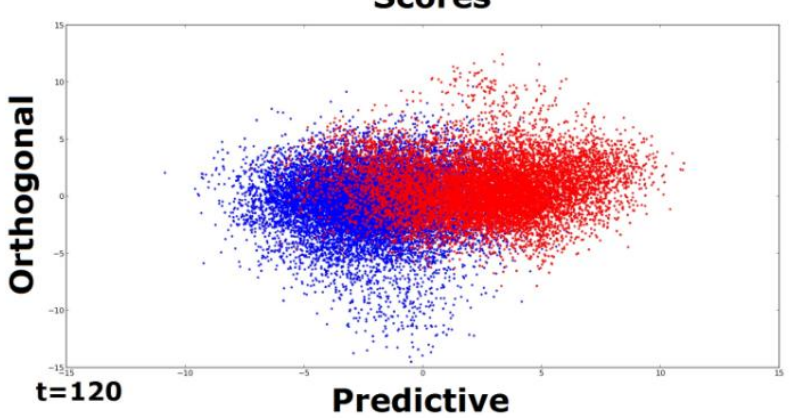

Supplementary Figure 3. Comparison of OPLS-DA scores plot from 2000 cross-validated models for bacteria treated with $125 \mu \mathrm{g} / \mathrm{ml}$ magainin 2 (A) or $62.5 \mu \mathrm{g} / \mathrm{ml}$ pleurocidin (B), against untreated control at $\mathrm{t}=5, \mathrm{t}=15, \mathrm{t}=60$, and $\mathrm{t}=120$ minutes. 


\begin{tabular}{|c|c|c|}
\hline \multicolumn{3}{|c|}{} \\
\hline Time (mins) & Pleurocidin & Magainin 2 \\
\hline $\mathbf{5}$ & $0.81(-0.31)$ & $0.51(-0.25)$ \\
\hline $\mathbf{1 5}$ & $0.86(-0.27)$ & $0.57(-0.30)$ \\
\hline $\mathbf{6 0}$ & $0.62(-0.27)$ & $0.48(-0.27)$ \\
\hline $\mathbf{1 2 0}$ & $0.70(-0.24)$ & $0.49(-0.25)$ \\
\hline
\end{tabular}

Supplementary Table 1. Predictive $Q^{2}$ values for OPLS-DA models obtained during the time-course experiment and corresponding to the OPLS-DA scores plots shown in Supp. Fig. 3. $\mathrm{Q}^{2}$ values for cross validation runs with permutated class assignments are given in parentheses.

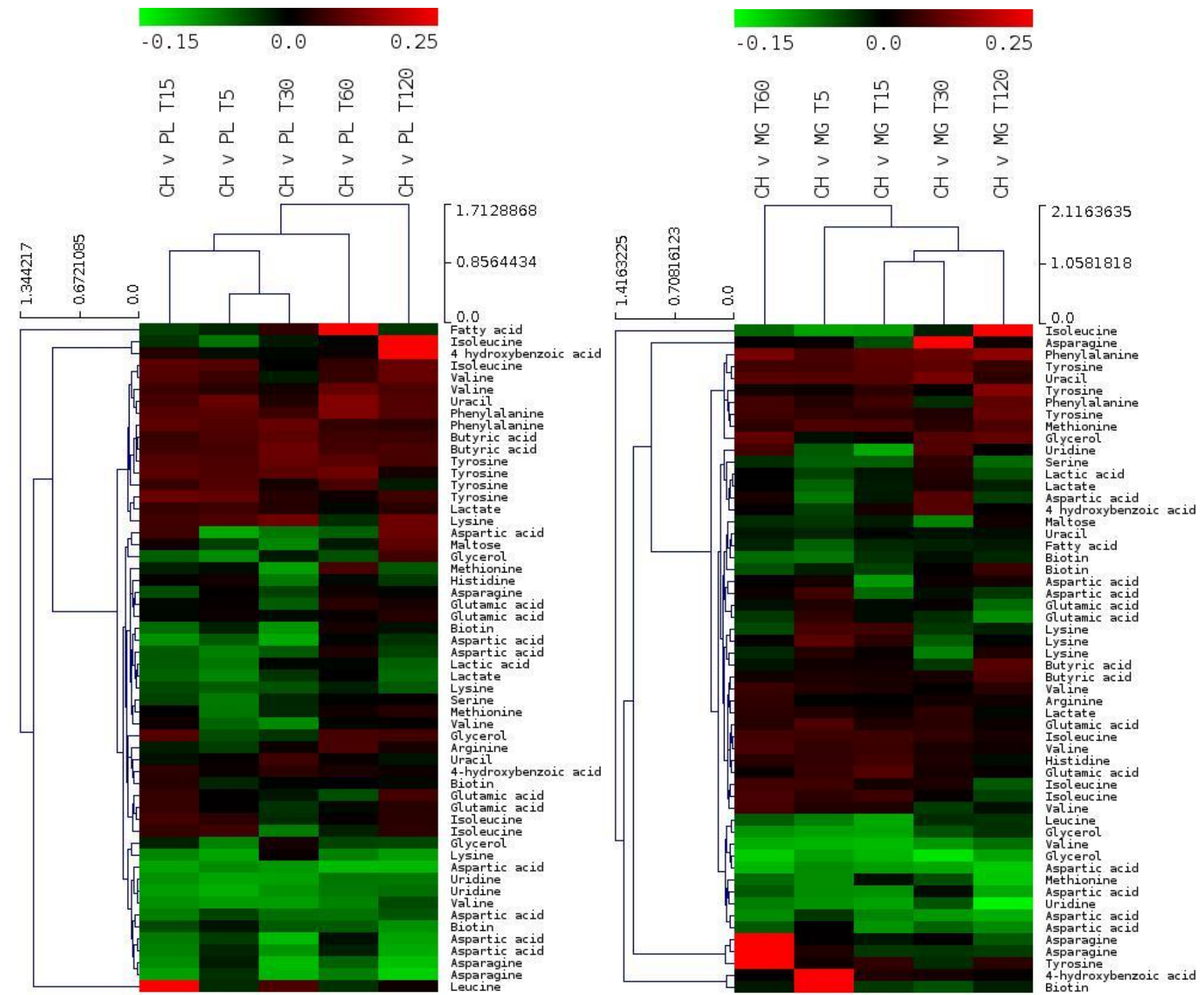

Supplementary Figure 4. Hierarchical cluster analyses of metabolic responses to pleurocidin (left) and magainin 2 (right) challenge recorded for five different incubation periods. The responses are broadly similar over time but, in particular for pleurocidin, there is a suggestion that a second phase can be detected after c 30 minutes 

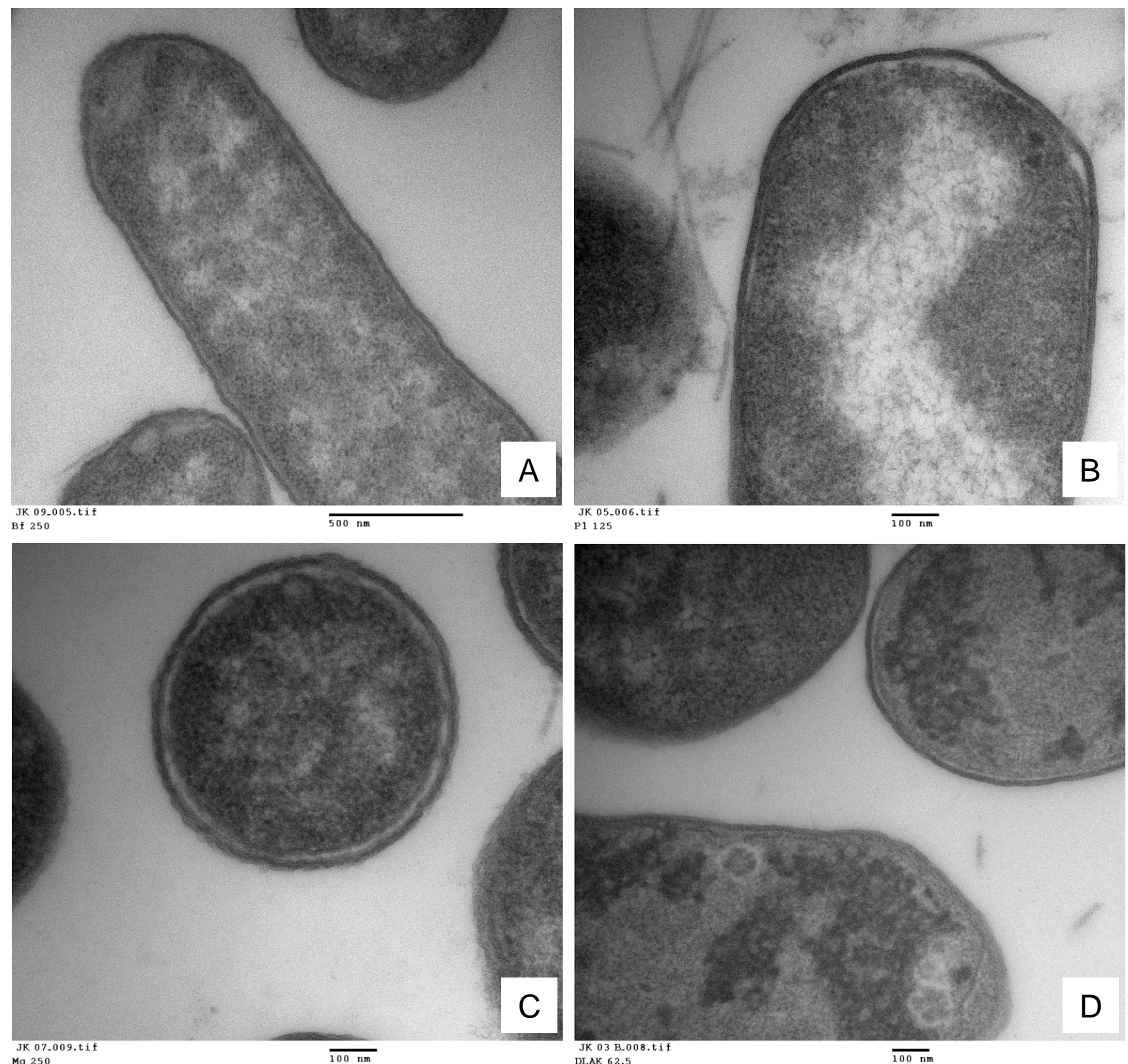

Mg 250

DLAK 62.5

Supplementary Figure 5.1 Transmission electron micrographs AMP challenged E. coli NCTC 9001. Bacteria were challenged for 30 minutes with AMPs above the threshold concentration that elicits a bacterial response as determined by the ${ }^{1} \mathrm{H}$ NMR metabolomic study; $250 \mu \mathrm{g} / \mathrm{ml}$ buforin II (A), $125 \mu \mathrm{g} / \mathrm{ml}$ pleurocidin (B), $250 \mu \mathrm{g} / \mathrm{ml}$ magainin 2 (C) and $62.5 \mu \mathrm{g} / \mathrm{ml}$ D-LAK120-AP13 (D). 

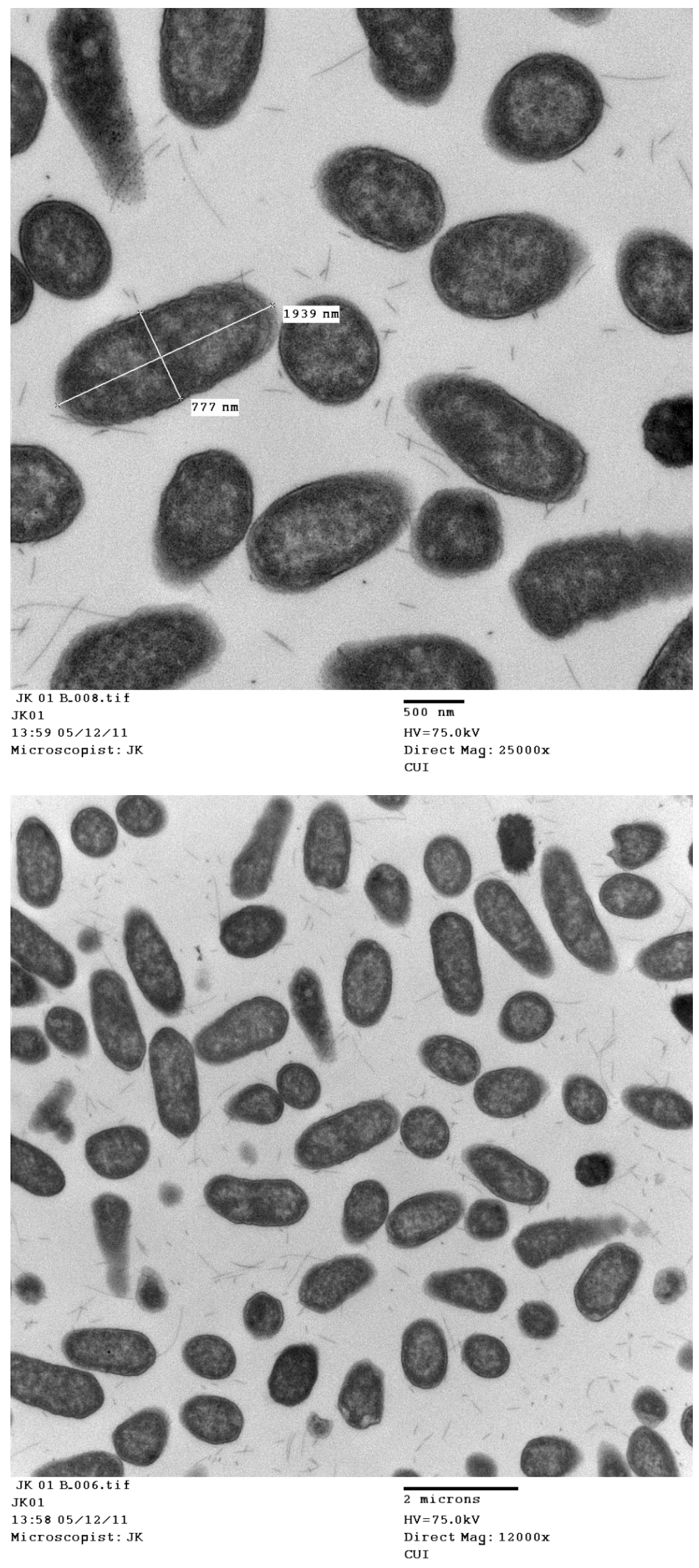

Supplementary Figure 5.2 TEMs of E. coli NCTC 9001 - control cells 

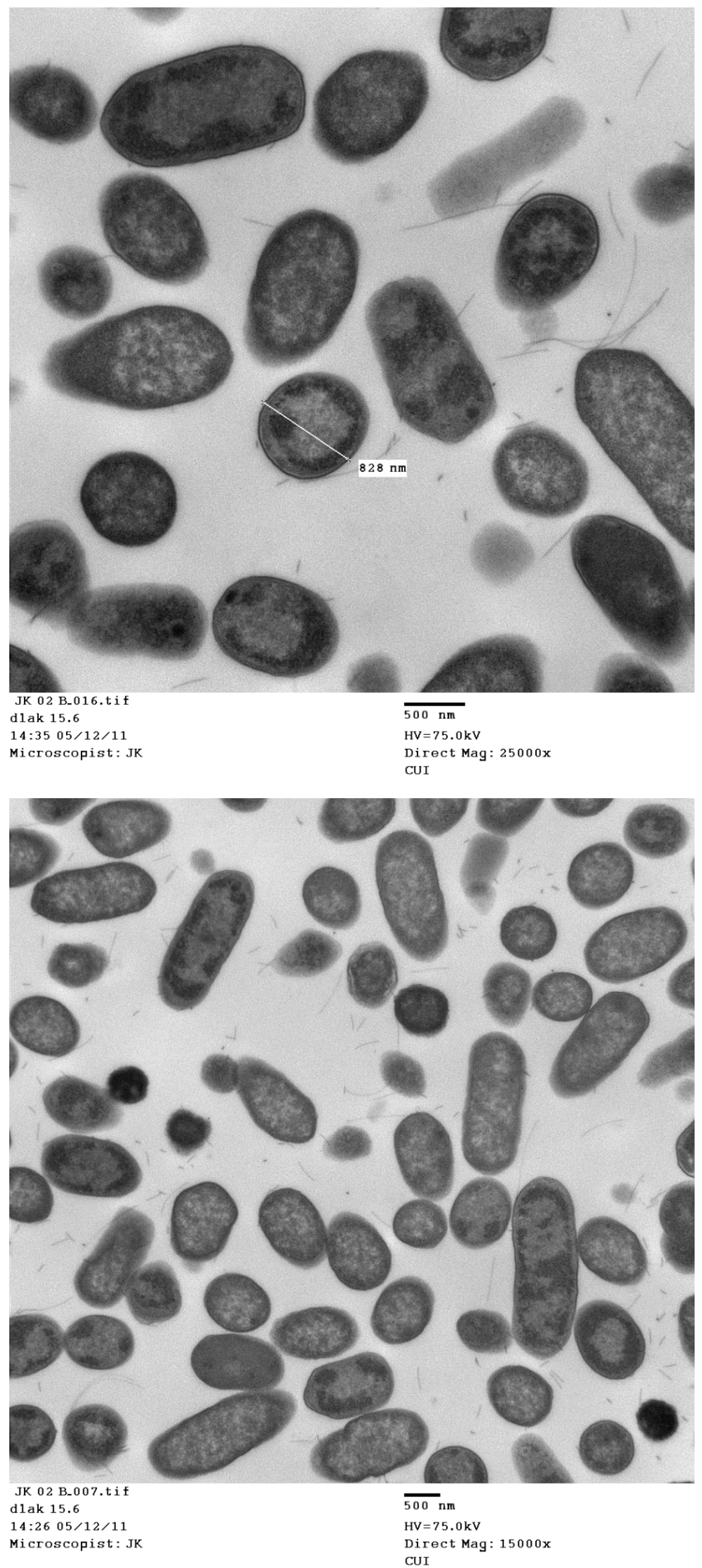

Supplementary Figure 5.3 TEMs of E. coli NCTC 9001 challenged with $15.6 \mu \mathrm{g} / \mathrm{ml}$ D-LAK120-AP13 

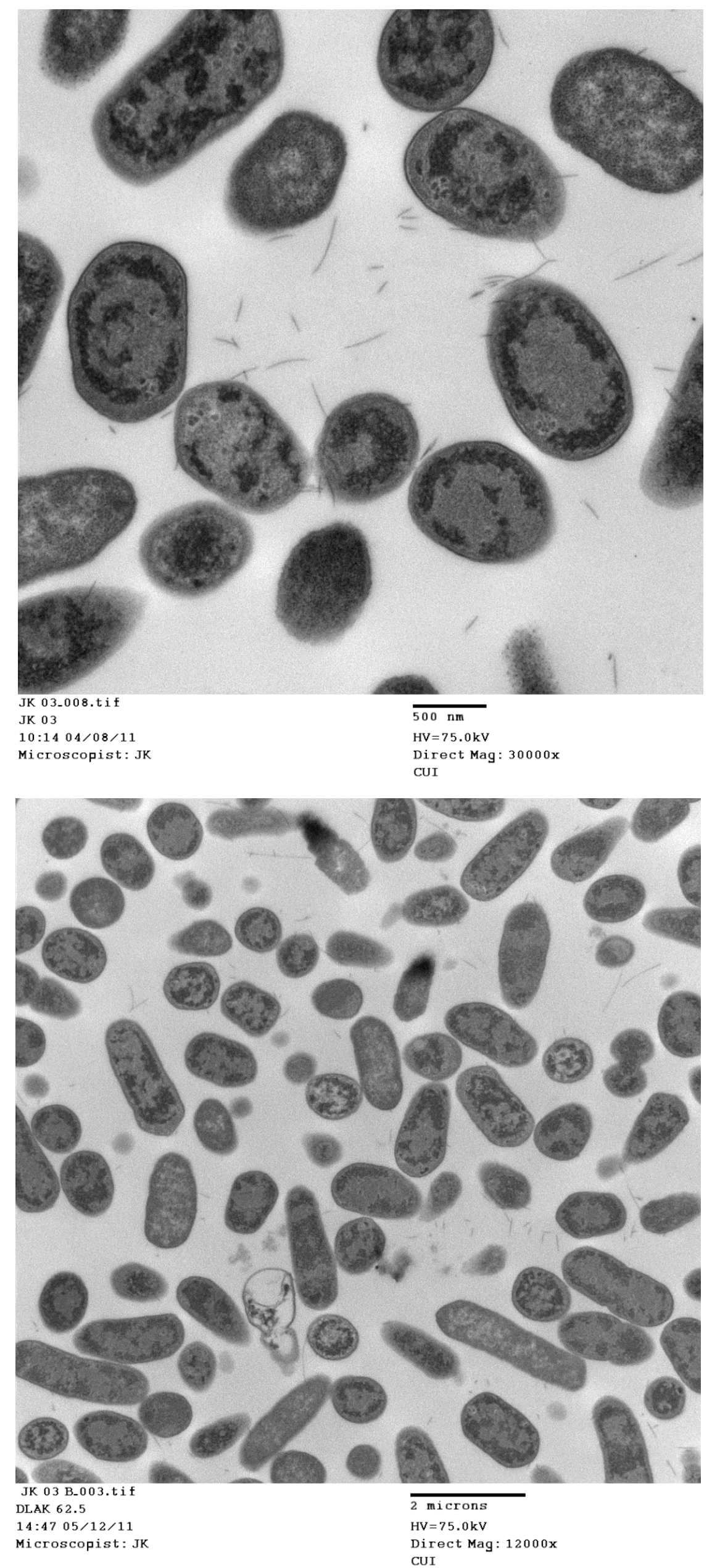

Supplementary Figure 5.4 TEMs of E. coli NCTC 9001 challenged with $62.5 \mu \mathrm{g} / \mathrm{ml}$ D-LAK120-AP13 


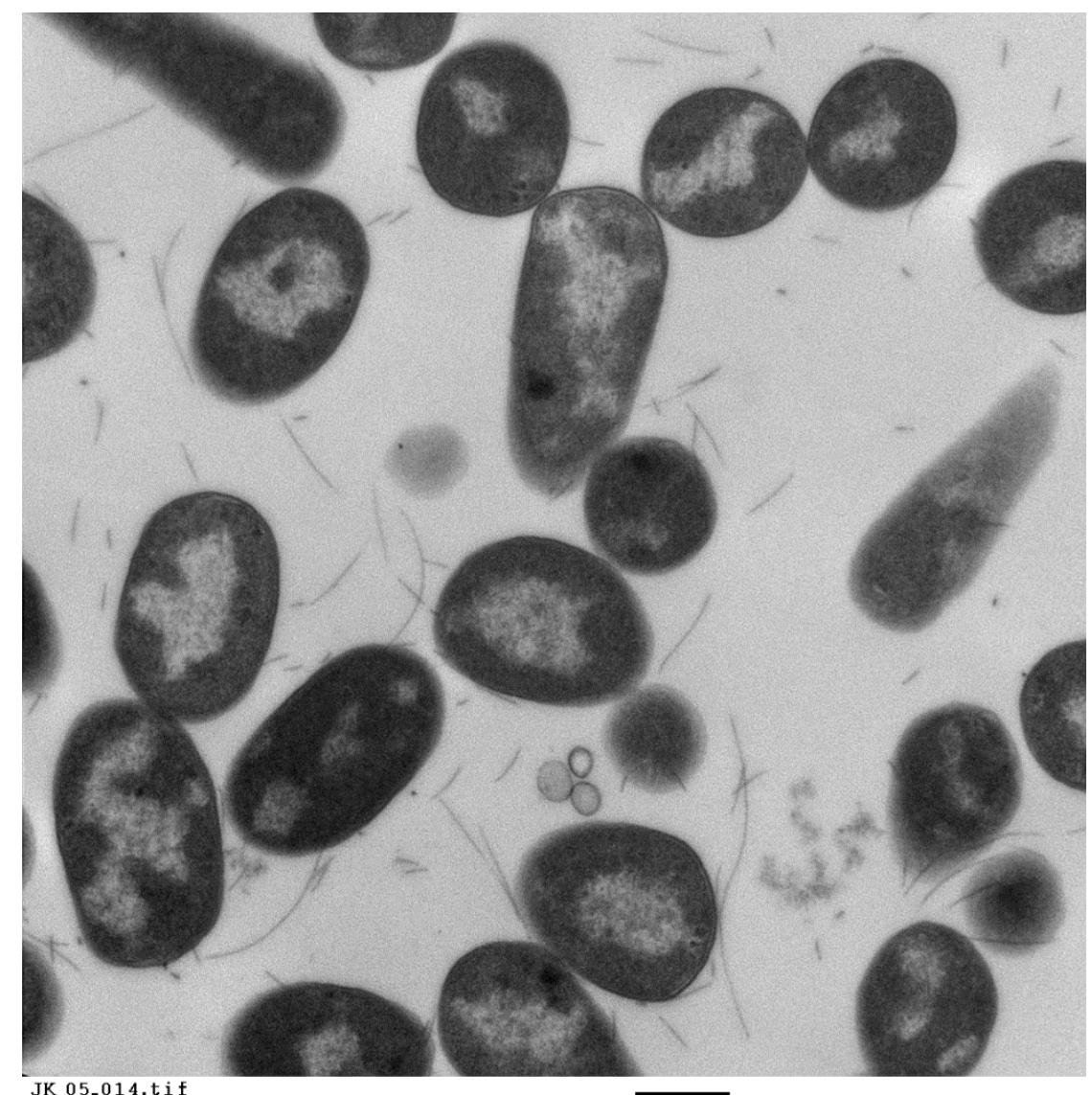

JK 05-014.tif P1 125

JK0 5

15:41 05/12/11

Microscopist: JK

$500 \mathrm{~nm}$

$\mathrm{HV}=75.0 \mathrm{kV}$

Direct Mag: $25000 \mathrm{x}$

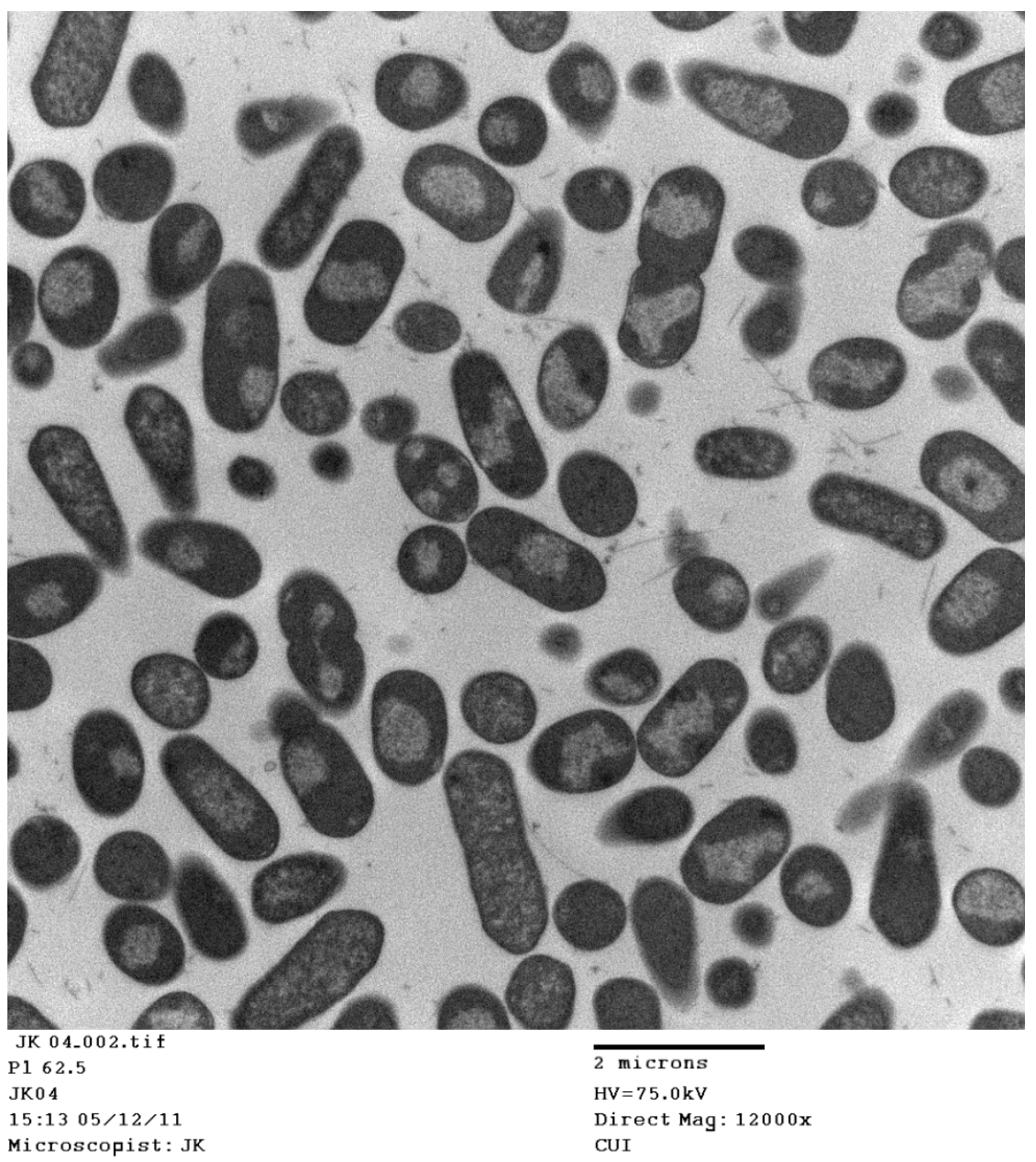

Supplementary Figure 5.5 TEMs of E. coli NCTC 9001 challenged with $62.5 \mu \mathrm{g} / \mathrm{ml}$ pleurocidin 

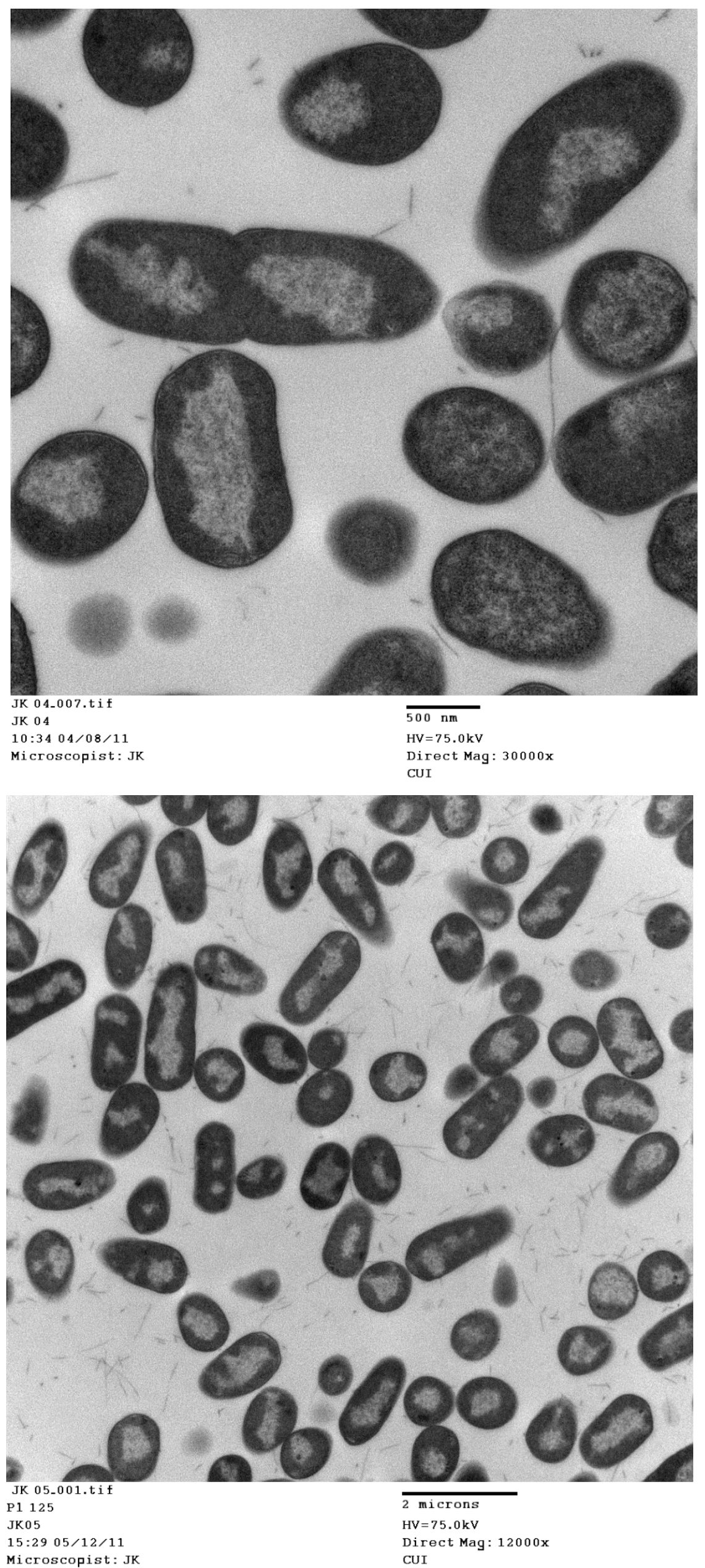

Supplementary Figure 5.6 TEMs of E. coli NCTC 9001 challenged with $125 \mu \mathrm{g} / \mathrm{ml}$ pleurocidin 

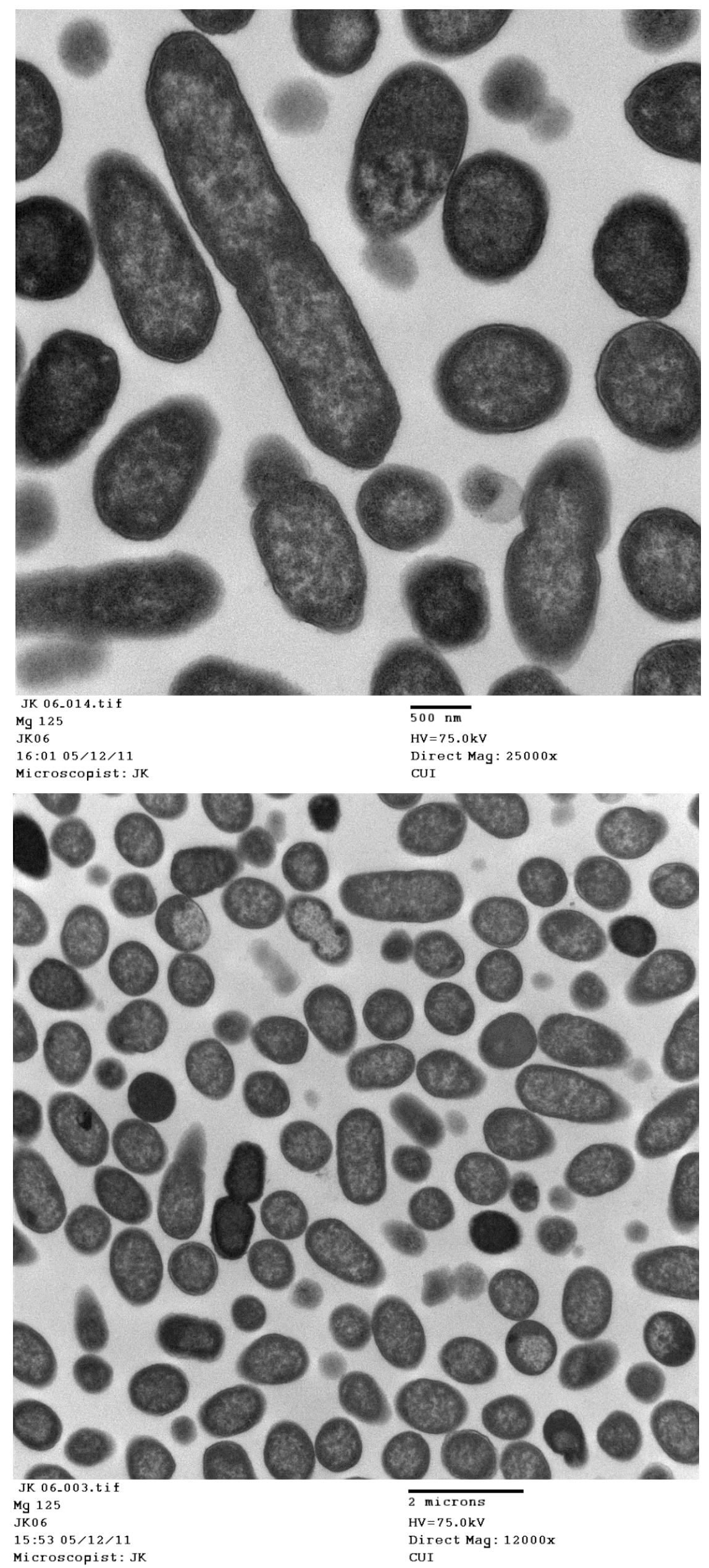

Supplementary Figure 5.7 TEMs of E. coli NCTC 9001 challenged with $125 \mu \mathrm{g} / \mathrm{ml}$ magainin 2 

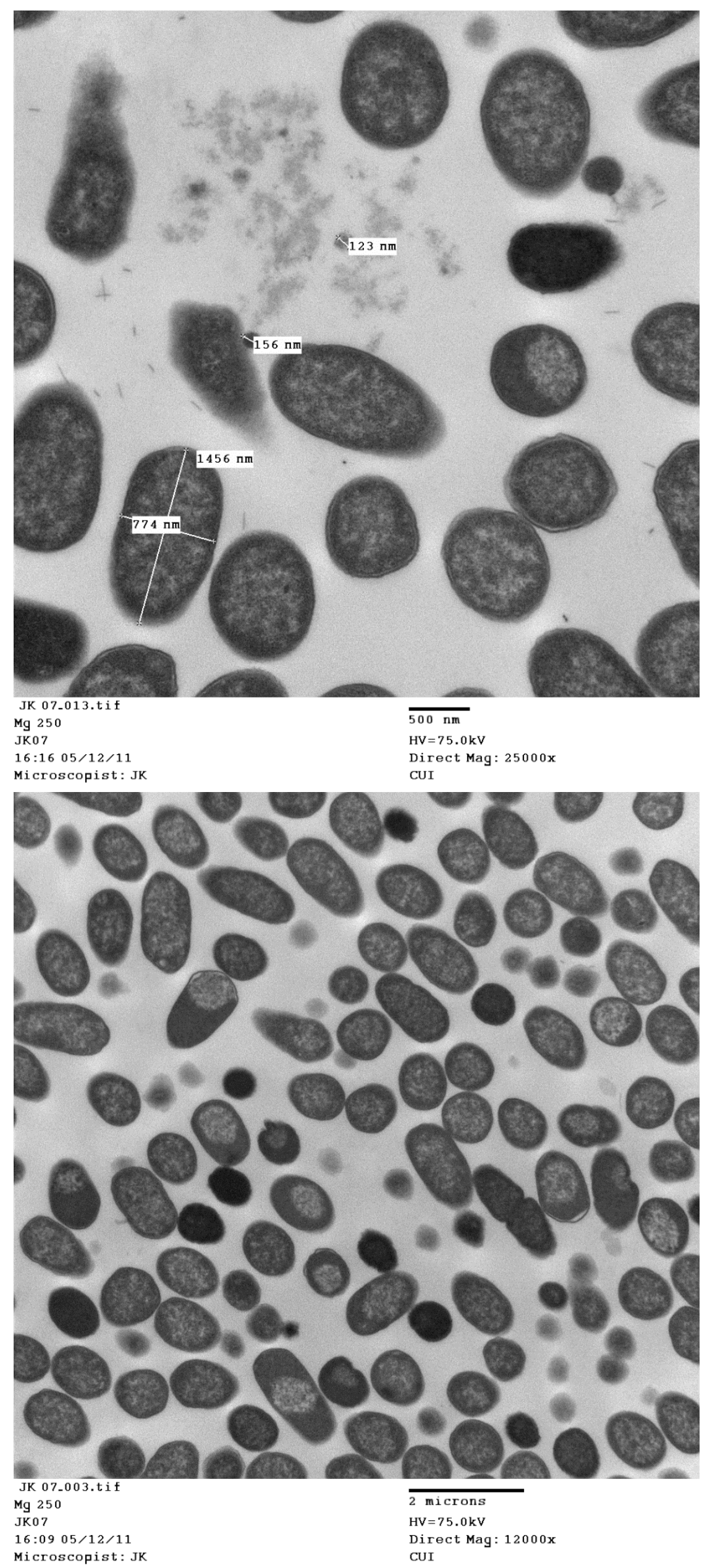

Supplementary Figure 5.8 TEMs of E. coli NCTC 9001 challenged with $250 \mu \mathrm{g} / \mathrm{ml}$ magainin 2 


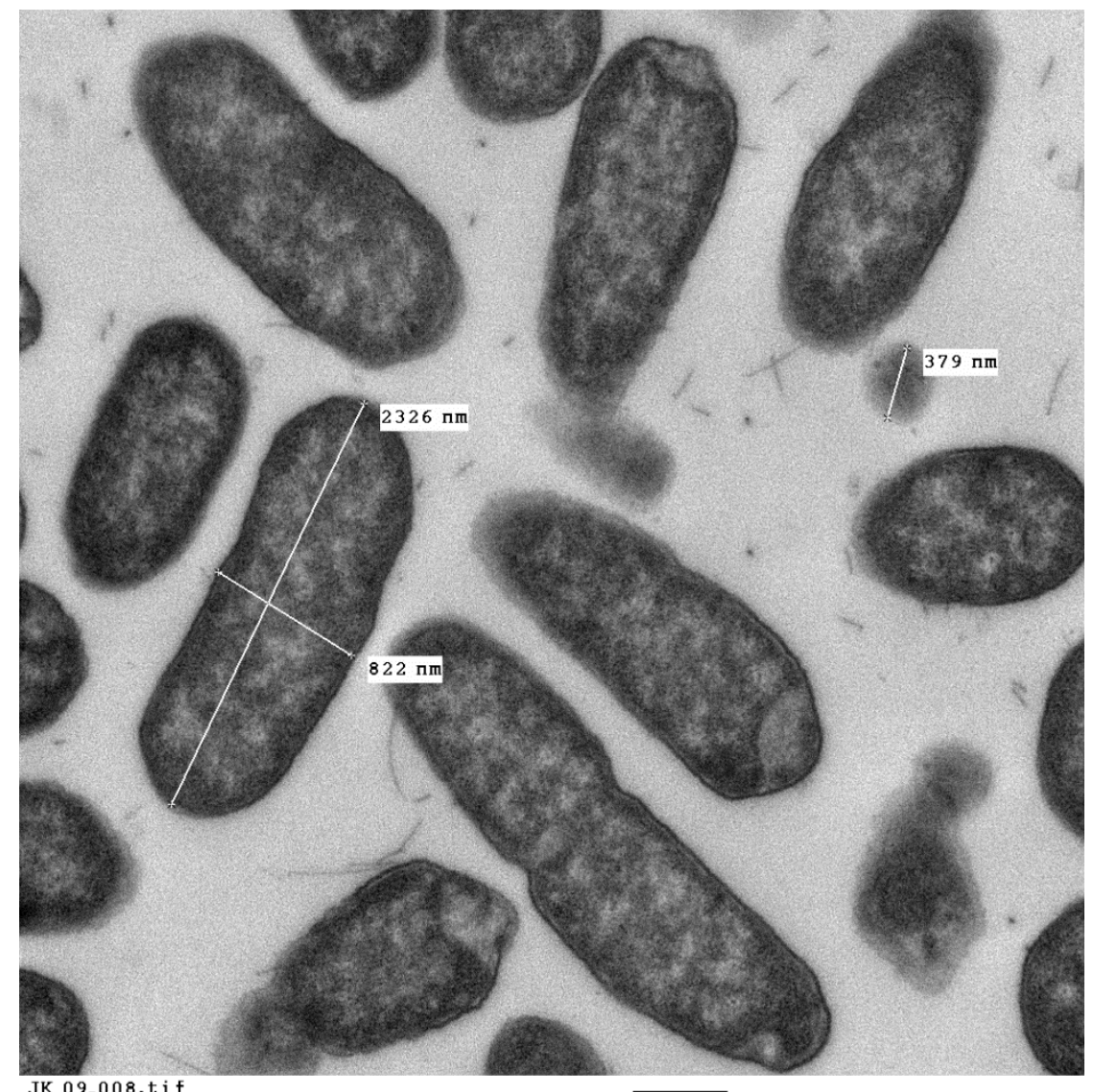

JK 09-008.tif Bf 250

JK0 9

16:50 05/12/11

Microscopist: JK
$500 \mathrm{~nm}$

$\mathrm{HV}=75.0 \mathrm{kV}$

Direct Mag: 25000x

CUI

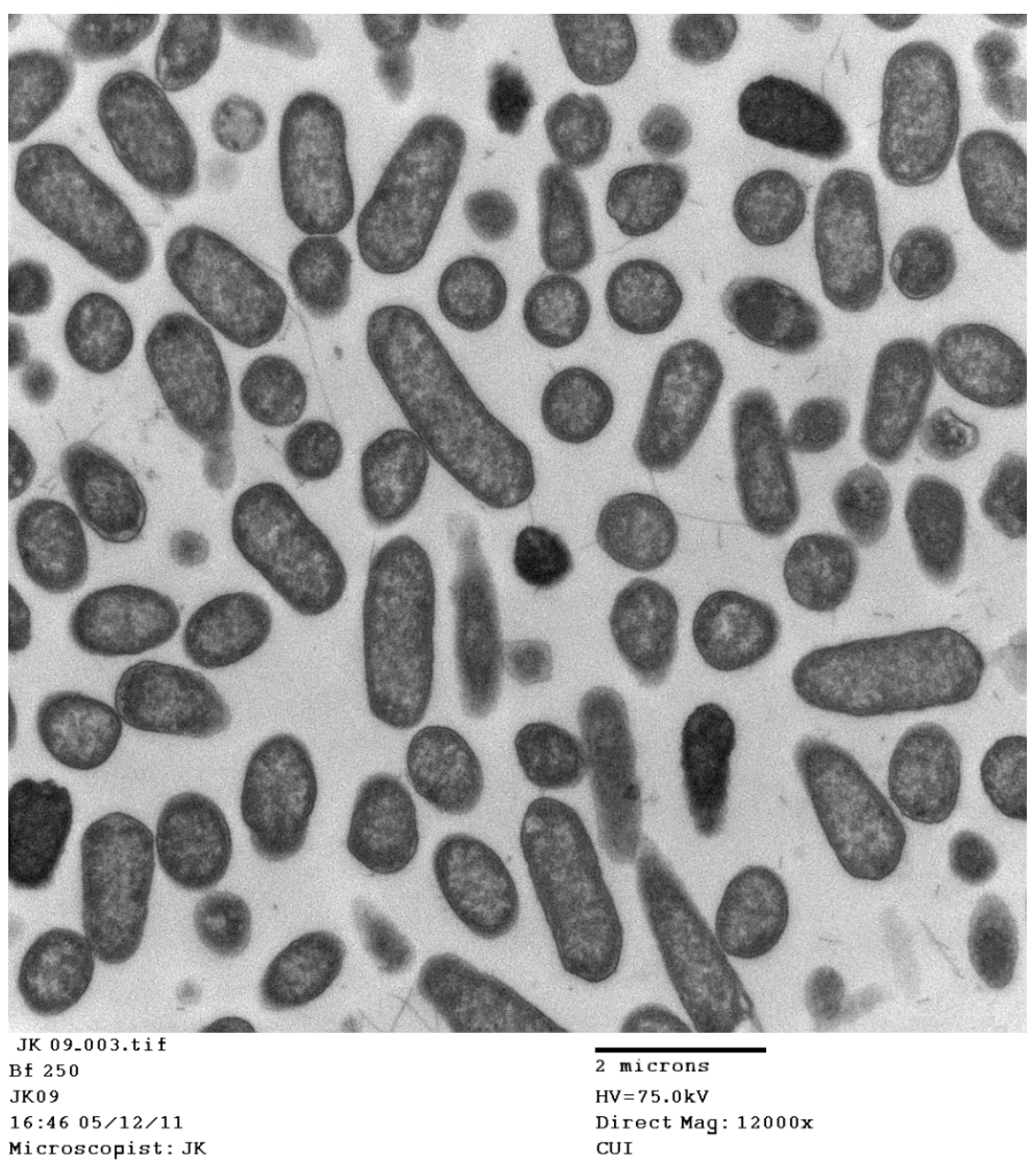

Supplementary Figure 5.9 TEMs of E. coli NCTC 9001 challenged with $250 \mu \mathrm{g} / \mathrm{ml}$ buforin II 

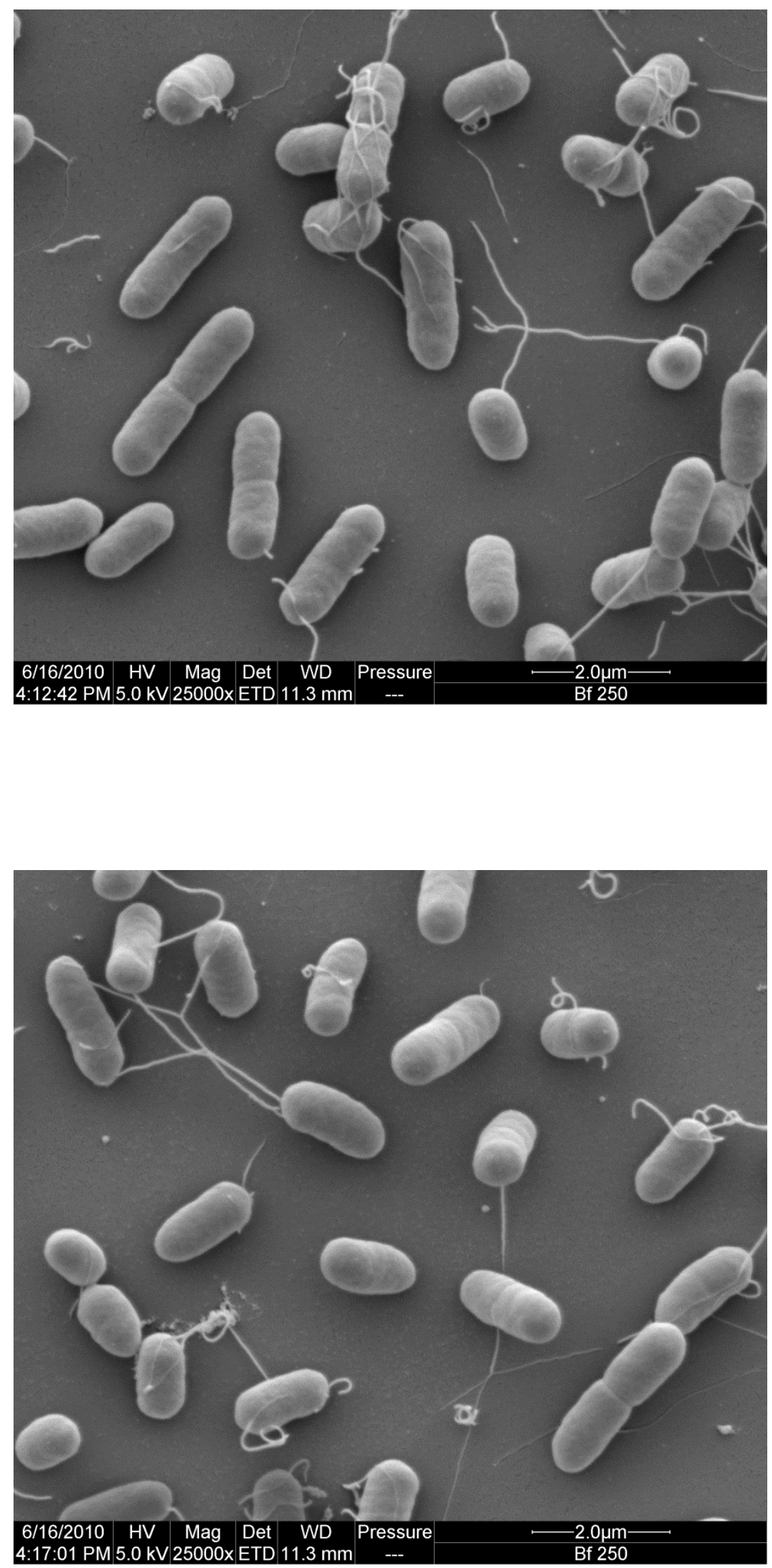


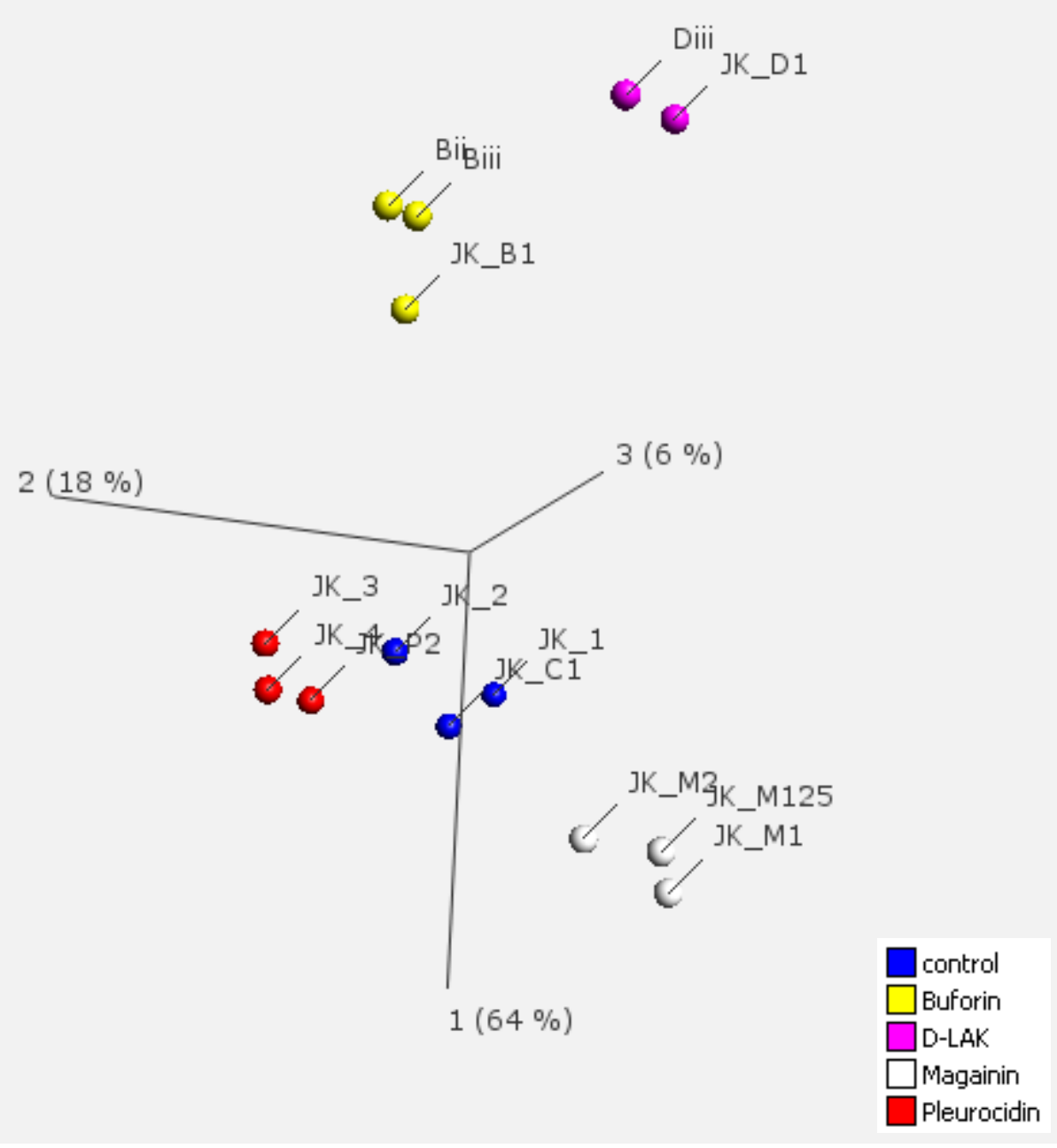

Supplementary Figure 6. Output from Qlucore Omics Explorer showing three dimensional Principal Component Analysis of 20 most differentially expressed genes across all 14 GeneChips for E. coli NCTC 9001 as detected by the GeneChip E. coli Genome 2.0 Array. Bacteria were challenged for 30 minutes with AMPs at the threshold concentration that elicits a bacterial response as determined by the ${ }^{1} \mathrm{H}$ NMR metabolomic study; $250 \mu \mathrm{g} / \mathrm{ml}$ buforin II, $62.5 \mu \mathrm{g} / \mathrm{ml}$ pleurocidin (B), $125 \mu \mathrm{g} / \mathrm{ml}$ magainin 2 (C) and 15.6 $\mu \mathrm{g} / \mathrm{ml}$ D-LAK120-AP13 (D). The axes $(1,2,3)$ relate to principal component 1 (PC1), PC2 and PC3 respectively and indicate how much variance is explained by each of these first three principal components. The plot indicates the reproducibility of the transcript profiling experiment by showing that variance in the 20 most different differentially expressed genes is closely related to the AMP challenge applied. 

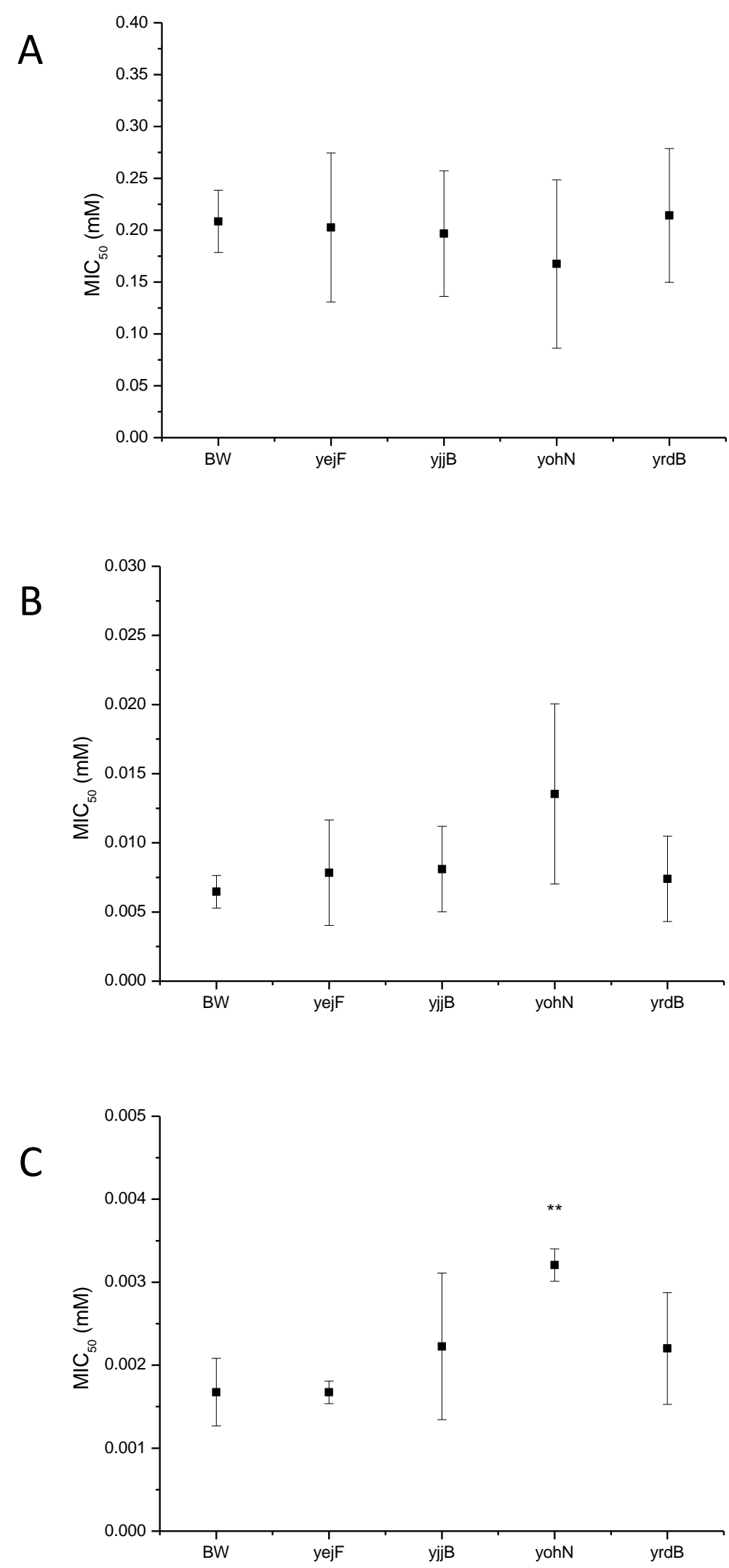

Supplementary Figure 7. Sensitivity of Wild type and four mutants from the Keio collection to different cations: (A) $\mathrm{MgCl}_{2}$, (B) $\mathrm{NiCl}_{2}$, (C) $\mathrm{CoCl}_{2}$. (**) $^{* *} \leq 0.05$ relative to BW. $\Delta y o h N$ confers sensitivity to $\mathrm{Co}^{2+}$ and possibly $\mathrm{Ni}^{2+}$. 


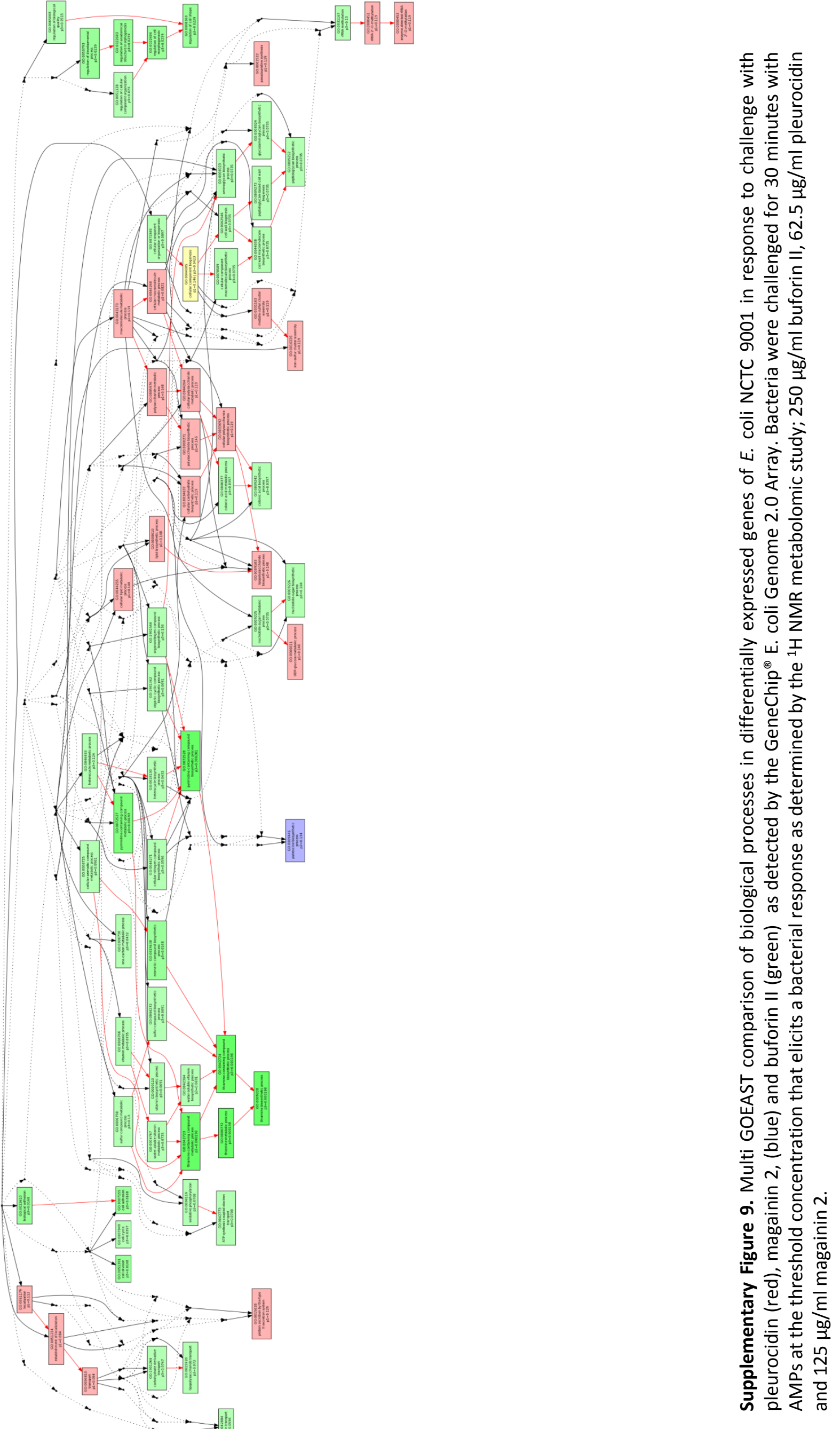




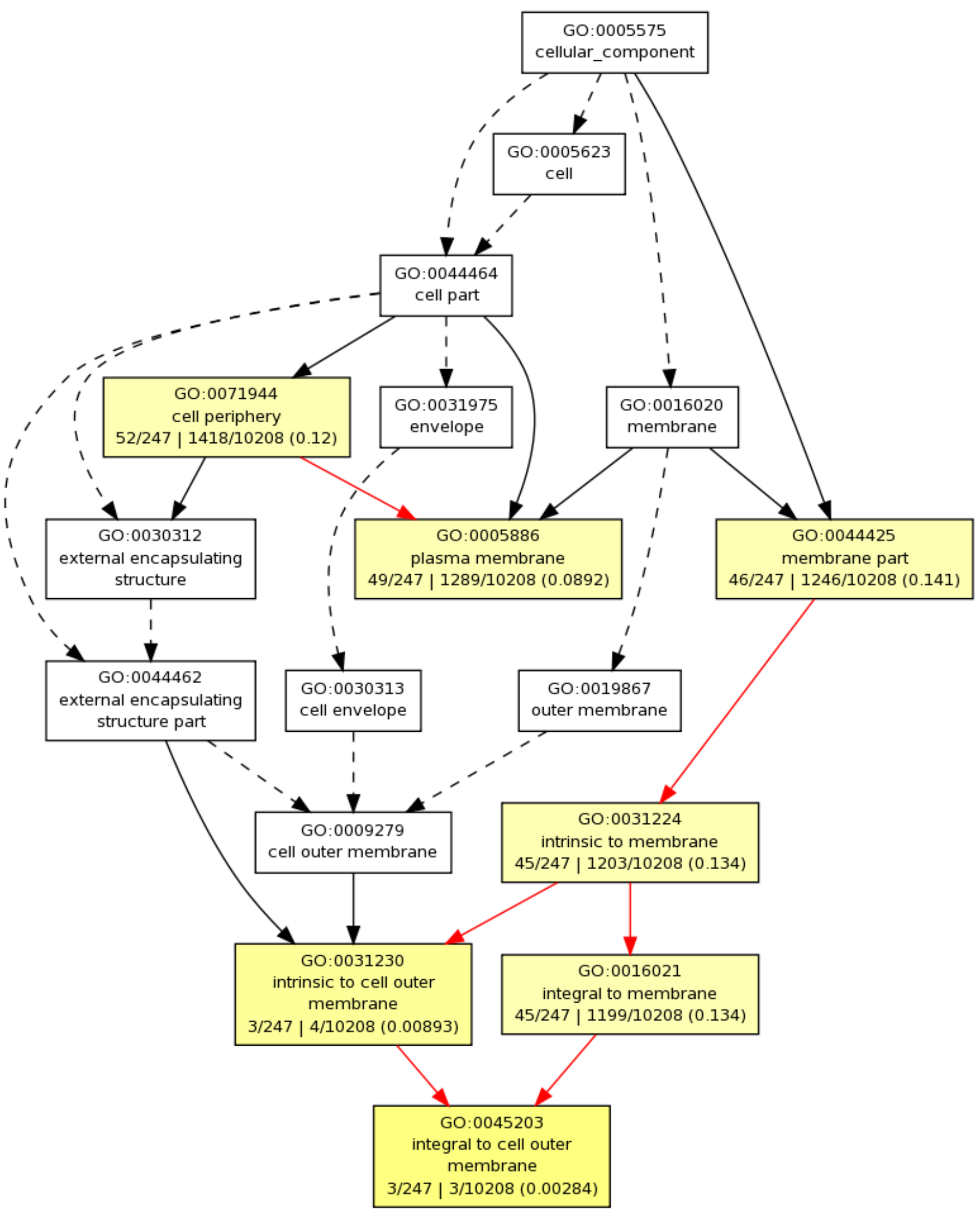

Supplementary Figure 10. GOEAST analysis of cellular component in differentially expressed genes of $E$. coli NCTC 9001 in response to challenge with magainin 2 as detected by the GeneChip ${ }^{\circledR}$ E. coli Genome 2.0 Array. Bacteria were challenged with $125 \mu \mathrm{g} / \mathrm{ml}$ magainin 2; the threshold concentration that elicits a bacterial response as determined by the ${ }^{1} \mathrm{H}$ NMR metabolomic study. 
A
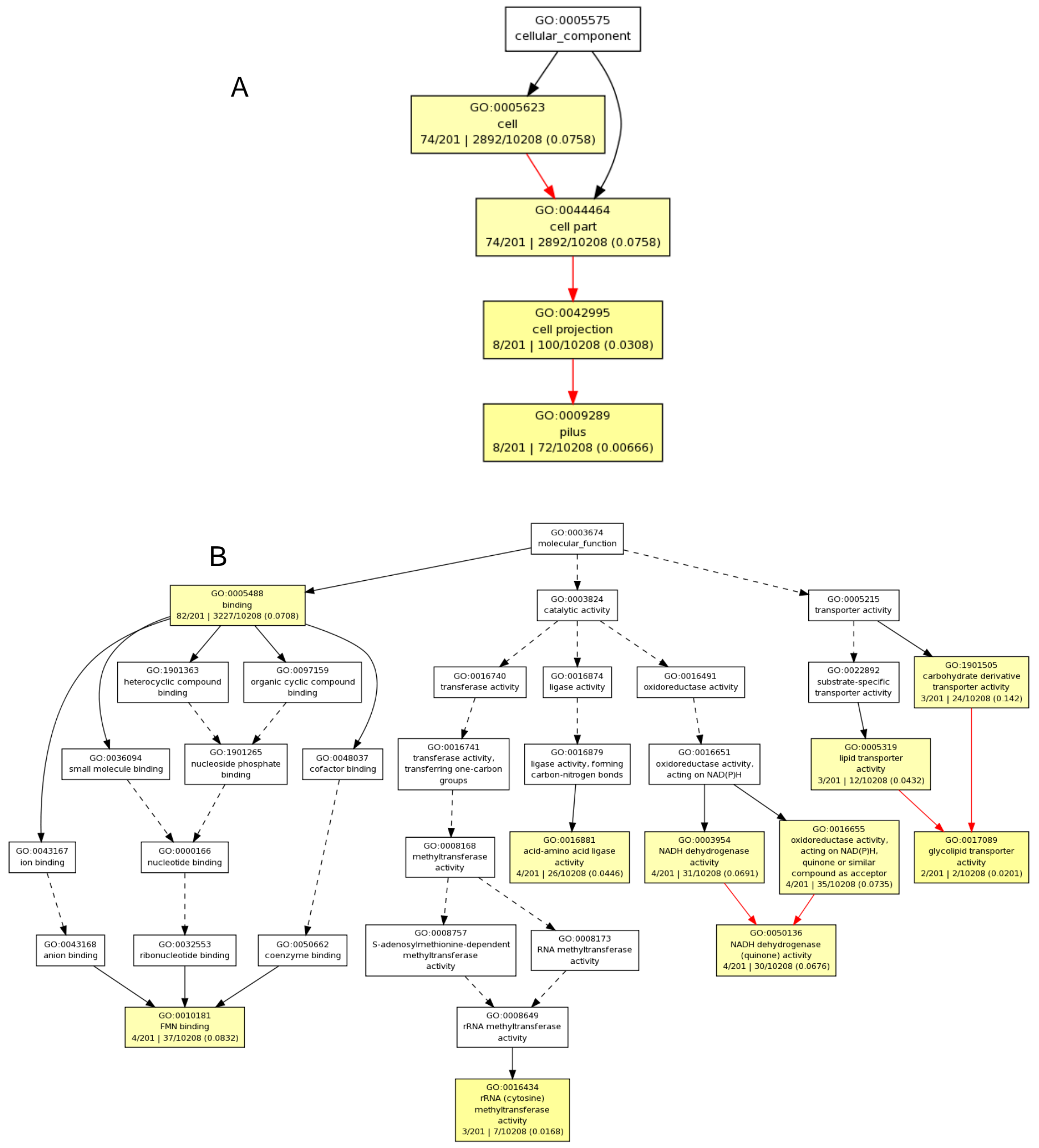

Supplementary Figure 11 GOEAST analysis of cellular component (A) and molecular function (B) in differentially expressed genes of E. coli NCTC 9001 in response to challenge with buforin II as detected by the GeneChip ${ }^{\circledR}$ E. coli Genome 2.0 Array. Bacteria were challenged with $250 \mu \mathrm{g} / \mathrm{ml}$ buforin II; the threshold concentration that elicits a bacterial response as determined by the ${ }^{1} \mathrm{H}$ NMR metabolomic study. Note the concentration of genes in cellular component GO terms "cell" or "cell part" and in molecular function GO:0005488 "binding". 


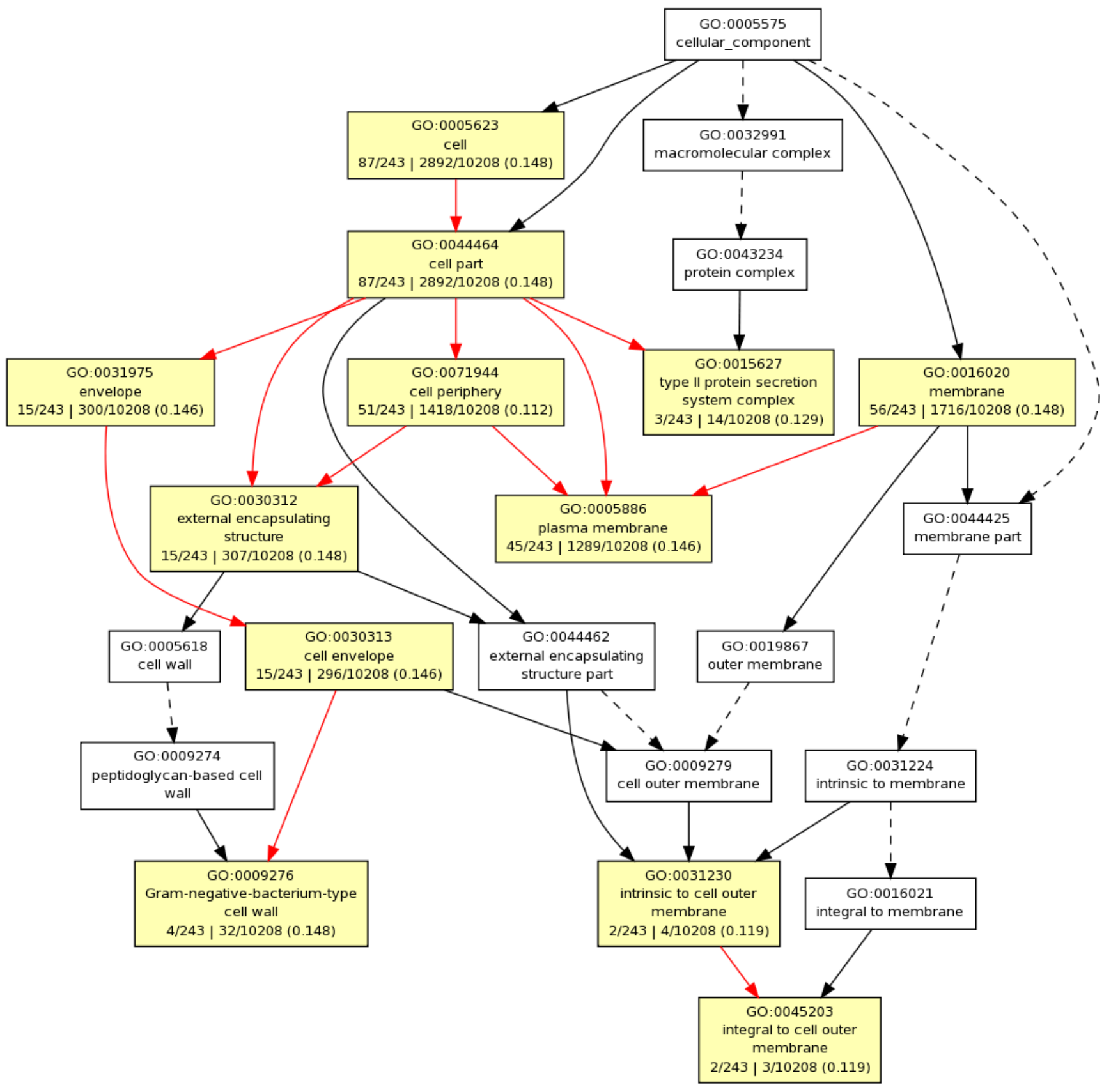

Supplementary Figure 12. GOEAST analysis of cellular component in differentially expressed genes of $E$. coli NCTC 9001 in response to challenge with pleurocidin as detected by the GeneChip ${ }^{\circledR}$ E. coli Genome 2.0 Array. Bacteria were challenged with $62.5 \mu \mathrm{g} / \mathrm{ml}$ pleurocidin; the threshold concentration that elicits a bacterial response as determined by the ${ }^{1} \mathrm{H}$ NMR metabolomic study. Note the distribution of genes between GO terms "cell"/"cell part", "cell periphery" and "membrane"/"plasma membrane". 


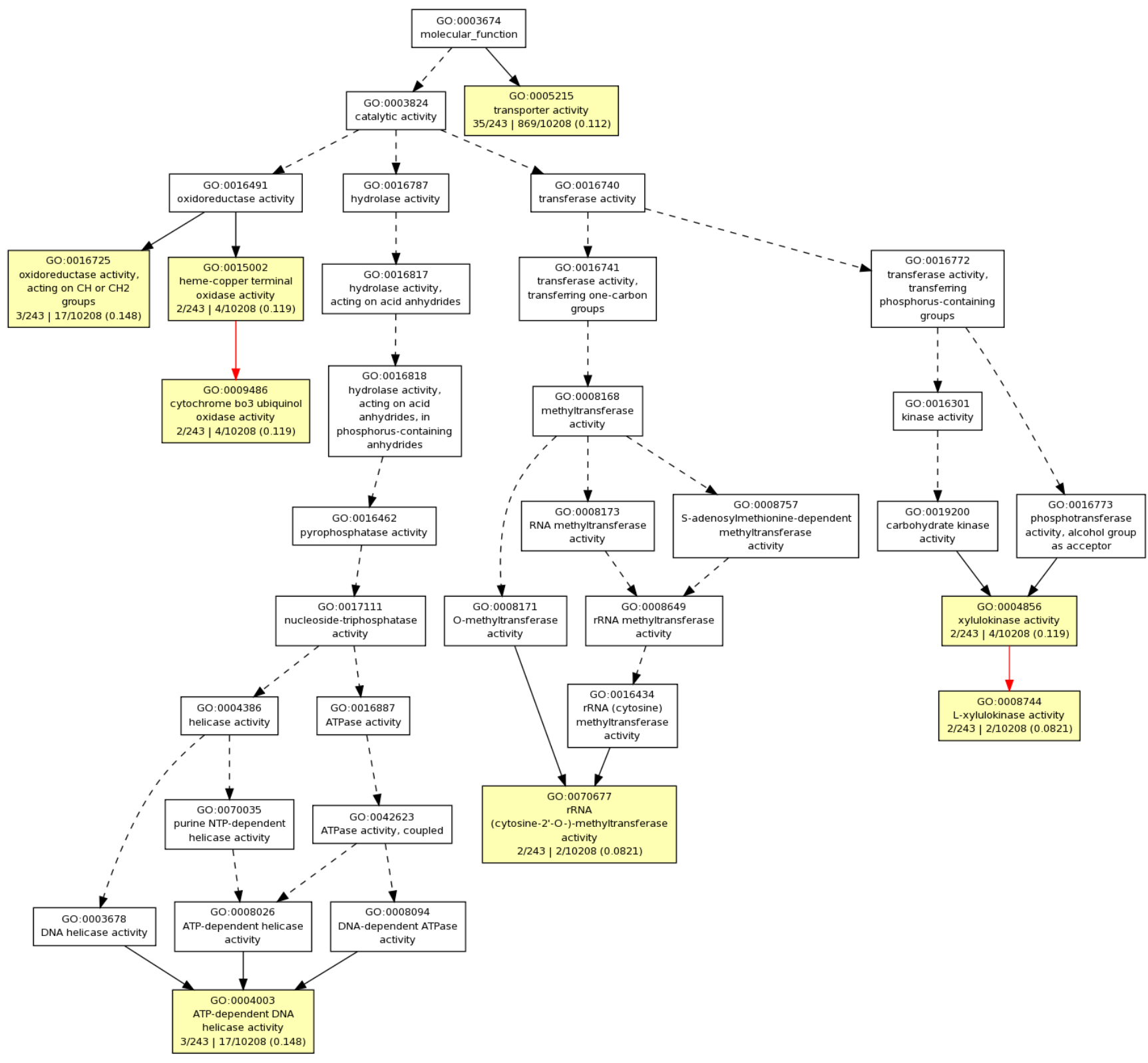

Supplementary Figure 13. GOEAST analysis of molecular function in differentially expressed genes of $E$. coli NCTC 9001 in response to challenge with pleurocidin as detected by the GeneChip ${ }^{\circledR}$ E. coli Genome 2.0 Array. Bacteria were challenged with $62.5 \mu \mathrm{g} / \mathrm{ml}$ pleurocidin; the threshold concentration that elicits a bacterial response as determined by the ${ }^{1} \mathrm{H}$ NMR metabolomic study. Note the high number of genes corresponding to GO:0005215 transporter activity. 